\title{
Farruco, Paco, Fran: datos históricos e evolución dos
} hipocorísticos en Galicia

\author{
Ana Isabel Boullón Agrelo \\ Universidade de Santiago de Compostela
}

\begin{abstract}
Resumo:
Os hipocorísticos, ou formas afectivas dos nomes persoais, apenas foron obxecto de estudo en Galicia ata agora. Neste traballo comézase reflexionando sobre a súa delimitación conceptual e as dificultades metodolóxicas para o seu estudo. Logo, examínanse os rexistrados en Galicia ao longo dos séculos, desde a Idade Media, os Séculos Escuros e o século XX ata as tendencias máis recentes. A partir deles faise unha análise dos procedementos de formación dos hipocorísticos máis tradicionais (a adxunción de sufixos, a supresión de sons, o uso de certas consoantes palatais, e outros) e considérase a influencia que sobre eles tiveron os cambios nas tendencias onomásticas dos últimos anos. Ao final reprodúcese a compilación das máis de 400 formas rexistradas.
\end{abstract}

\section{Palabras chave:}

Antroponimia, hipocorísticos, lingua galega.

\begin{abstract}
:
Hypocoristics, or affectionate forms of personal names, have scarcely been the subject of study in Galicia until now. In this work the author reflects upon their conceptual delimitation and the methodological difficulties posed by their study. Hipocoristics registered in Galicia during the course of several centuries are examined, from the period of the Middle Ages, to the so-called Dark Centuries and the twentieth century until more recent trends. Processes associated with the formation of more traditional hipocoristics are analyzed (the addition of suffixes, suppression of sounds, use of certain palatals consonants, etc.), with especial emphasis places on the influence that changes in naming trends have exercised upon them in recent years. Finally, the compilation of the more of 400 forms is reproduced.
\end{abstract}

Key words:

Personal names, hipocoristics, Galician language.

\section{Delimitación do concepto de hipocorístico}

Os hipocorísticos son variantes formais dun prenome, que se comezan a usar no ámbito familiar e teñen orixe nos hábitos articulatorios da linguaxe infantil. 
Comparten características cos alcumes, por seren ámbalas dúas denominacións alternativas á oficial, non sistemáticas, que se dan nun ámbito máis ou menos reducido ao redor do portador. Pero os alcumes son propios das áreas rurais e vilegas, motivados ao principio e moitas veces hereditarios; pola contra, os hipocorísticos están estendidos a tódolos ámbitos sociais e poboacionais, créanse a partir das características formais do prenome (ou repiten unha forma xa consabida), e raras veces son hereditarios, porque, con frecuencia, deixan de usarse máis alá da adolescencia ou fóra do ámbito familiar. Isto non significa que algúns deles non poidan converterse propiamente en alcumes que acompañan o portador durante toda a súa vida, e nalgúns casos, coma os alcumes, tamén se fan hereditarios, ata esquecerse a motivación ou o nome último que os orixinou.

Este carácter 'cariñoso', 'diminutivo' que está na orixe etimolóxica da palabra', pode obstaculizar a súa identificación, porque tódolos nomes propios son, en principio, susceptibles de portar sufixos de carácter expresivo que reflicten unha actitude de tenrura cara á persoa que o leva; nese caso está, por suposto, o sufixo diminutivo por excelencia, -iñalo (Carmiña), pero tamén outros que practicamente só se usan cos antropónimos (como en Quicocho, Xanzolas), e que se poden empregar de maneira asistemática, só en determinadas ocasións. Esa é a razón, seguramente, do uso de certos diminutivos, normalmente expresados co sufixo -iño, que se observan nos textos literarios, como o Barbuliña co que se refire Sarmiento [1746] á princesa portuguesa esposa de Fernando VI, Bárbara de Braganza. Nesta recollida procurei ter en conta non tódalas posibilidades do sistema de aplicación de sufixos ás bases antroponímicas, senón só aquelas formas que semellan ser usadas como a denominación principal da persoa no seu ámbito social máis próximo.

Por outro lado, hai hipocorísticos que foron considerados como as formas galegas do nome correspondente, posiblemente por un certo afán diferencialista. O propio Saco, na súa Gramática (1868: 235-7), só indica propiamente como “diminutivos" Perucho e Maruxa, pois para o cast. José propón como equivalentes Pepe e mais Xepe, Farruco e Fuco para Francisco, ou Chinto para Jacinto, aínda que parece facer unha distinción entre Xan (equivalente a Juan) e o nome do santo, que é san Xoán. Estando a lingua galega asociada durante tanto tempo ao ámbito estritamente familiar ou rural, tampouco é de estrañar que estas formas, as usadas realmente pola xente, fosen consideradas as autenticamente galegas. Así o demostra Vicente Turnes, quen en 1846, no seu poema "Aos augustos desposorios de Isabel II e Luísa Fernanda de Borbón”, chámalle Sabela e Sabeliña á raíña, e ao seu desposado, Farruco de Borbón ou Farruco de Asís (Dobarro Paz 2000). E aínda antes, nos poemas das Fiestas Minervales (1697: 47), Joseph Guerrero Lasso de la Vega chámalle dona Sabel á raíña católica.

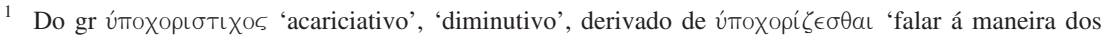

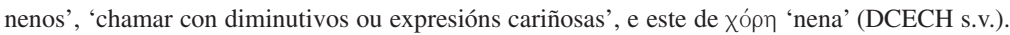


Esta perspectiva, que xa foi corrixida nos últimos tempos, ao conseguir a lingua outros ámbitos e outros usos, mantívose, porén, nalgúns casos: hoxe está moi estendida a crenza de que Catuxa ou Sabela son as formas galegas estándares ${ }^{2}$, como tamén o entendía Saco (1868: 235), aínda que en orixe son as formacións hipocorísticas de Catarina e Isabel, respectivamente. A máis antiga mención de Catuxa localizada ata agora, en 1756, dá luz ao respecto: o cura de Fruíme dedicáballe a " $\mathrm{D}^{\mathrm{a}}$ Catalina Garinverti y Cárdenas" un poema onde lle chamaba Catuxiña, con ocasión do seu santo: "Dios che dè por muitos anos / os días da túa santa / miña santa Cataliña" (Pardo de Neyra 2002: 170); daquela, usa unha forma en castelán, Catalina, unha galega, posiblemente considerada hipocorística, Catuxa, e outra, tamén galega, como nome da santa, Cataliña ${ }^{3}$. En realidade, a mudanza da consideración sociolingüística de certas formas non é un fenómeno estraño: é relativamente frecuente a conversión de hipocorísticos en nomes "formais", isto é, aptos para o rexistro civil, e, de feito, constitúe unha das maneiras actuais de renovar o corpus onomástico (véxase, por exemplo, DNG 1992: 31 e Boullón Agrelo 2007: 106).

\section{Dificultades metodolóxicas para o estudo dos hipocorísticos}

O carácter non oficial destas formas dificulta en boa medida a súa colleita, pois non se consignan nos catastros antigos, nos censos oficiais das oficinas de estatística nin nas guías telefónicas, por citar algúns lugares usuais de recompilación de datos antroponímicos. Cómpre recorrer, logo, a fontes indirectas, que se detallan na relación bibliográfica final. En primeiro lugar, á literatura: para o séc. XVIII, é cita inexcusable Sarmiento (que nos ofrece unha relación dos nomes e hipocorísticos galegos que el consideraba máis representativos no seu Coloquio en mil duascentas coplas galegas). No XIX, os textos das Tertulias ou Parolas ${ }^{4}$, as alusións feitas nas gramáticas decimonónicas (especialmente a de Saco (1868), pois Valladares reproduce practicamente as súas apreciacións) e mais outros textos literarios da época, como advertiu Fernández Salgado (no prelo):

2 De feito, no Censo do Instituto Nacional de Estadística (Madrid) do ano 2001, hai 120 ocorrencias de Catuxa fronte a 114 de Catarina e 780 de Catalina; e 1.276 de Sabela fronte a 12.534 de Isabel. Non hai, porén, ningunha ocorrencia de Farruco -quizais moi asociado ao ámbito rural-, aínda que si 3 de Fuco. Tódolos datos onomásticos citados de aquí en diante están tirados das bases de datos da Sección de Onomástica do ILG.

3 Esta variante está tamén documentada en textos medievais do s. XV, en DocDevOurense, CDRamirás, LNotasRianxo e CDNoia, se ben a maioritaria era Catalina (aínda que o grafema $<$ n $>$ podía nesta época tamén indicar nasal palatal, como é sabido); a forma con $r$ documentámola só unha vez (Katarina, nun texto escrito en latín en CDRamirás). Ademais, Cataliña perviviu na toponimia e como advocación relixiosa: Santa Cataliña (Muros-C), A Cataliña (Salvaterra-P), Santa Cataliña de Armada (Santa Comba-C), Santa Cateliña (Cartelle-Ou).

4 Moitos destes textos foron recollidos na colectánea Prosa galega da Universidade de Santiago (1976). 
Fixemos un reconto dos nomes dos personaxes que aparecen en 30 narracións dos 16 primeiros autores que figuran na colectánea dirixida por M. Hermida (2003) Narradores ocasionais do século XIX (Relato breve), e estes son os resultados. Os nomes de home que aparecen en máis de dous personaxes, por orde e agrupados sen ter en conta o hipocorístico, son: Farruco, Francisco ou Fuco (que o levan 8 personaxes), Pedro ou Perucho (7 p.), Pepe ou Xosé (5 p.), Antón (5 p.), Xan (4 p.), Caietano ou Queitano (2 p.), Bertoldo (2 p.) e Andrés (2 p.); estraña que Manuel só sexa o nome dun personaxe. Entre as mulleres, os máis frecuentes son: Marica (nome de 6 personaxes), Pepa (4 p.), Rosa (2 p.) e Xoana (2 p.).

Como fontes modernas, acudimos ao espolio de varias obras de recollida da fala popular, coma A nosa fala e o Cancioneiro popular 5 . Despois, fóra de traballos de campo específicos (moi poucos deles publicados, salvo os de Iglesias González 2005, ou Hafner 2004, que só parcialmente se ocupa de Galicia), recollidas de alcumes (como as de Torres Regueiro / Cuns 1989; Santos Gayoso 2002), ou a relación do DNG (1992: 593-598), o lugar impreso onde se rexistran é nas necrolóxicas dos xornais, que son especialmente útiles, pois dan datos moi precisos (idade e mais lugar de residencia) e, ademais, con elas tense a constancia de seren efectivamente as formas que máis identificaban o finado no seu contorno, tendo a mesma funcionalidade cós alcumes.

Por outra banda, unha dificultade engadida, que se ten tamén con outras formas lingüísticas procedentes de rexistros coloquiais (como a fraseoloxía), é a de distinguir formas que proceden do castelán das xenuinamente galegas, pois moitas non se poden xebrar foneticamente (como Lalo, Chencho). Quizais se deba facer valer aquí o criterio cronolóxico, pois posiblemente as máis recentes se deban ao influxo do castelán. Por exemplo, os hipocorísticos tradicionais de Francisco en galego eran Farruco $^{6}$ e Fuco (e así aparecen nos textos decimonónicos); a forma Paco, se

5 Os datos onomásticos desta fonte foron amablemente proporcionados por Antón Santamarina, a quen llo agradezo desde aquí.

6 Pensado (1991) pensa que é de orixe castelá, por figurar desde 1791 nos dicionarios da Real Academia Española, aínda que a partir de 1852 veña coa marca "provincialismo de Asturias y Galicia", e de que as atestacións máis antigas, que el mesmo proporciona, foron feitas por Fr. Pereira de Novais, "que escribe en Santiago entre 1662 e 1690", quen explica que "oy en dia estemos corrompendo el nombre de Francisco en Farruco y el de Fernando en Fernanduco". Na Idade Media funcionaba unha forma moi semellante tamén como hipocorístico (Stephanus Petri miles dictus Ferrucus a.1253 CDOseira $704=$ Stevao Perez Ferruco a.1298 CDOseira 1271), pero non correspondía a Francisco, porque este nome, se ben se documenta na Idade Media, por causa do santo de Asís (Frãcisco Lopez notario publico de Lugo a.1308 CDMaia 84, Francisq $<u>o$ Marino a.1422(or.) DocNoia $74 n^{\circ} 35$ ), acadou a súa popularidade grazas a Francisco Xavier (morto en 1522); de feito, no XVIII era o $2^{\circ}$ nome máis popular en Galicia (véxase o cadro do punto 7). Actualmente tamén é voz común: "farruco -a $a d x$. 1. Que manifesta insolencia, arrogancia e atrevemento na maneira de comportarse ou pola actitude que adopta. 
non era orixinariamente galega, adaptouse plenamente, como nos mostra o derivado Pacucho; porén, as formadas ca reduplicación da última sílaba, como Quico ou Queco parecen moito máis recentes, e aínda máis Fran, formada por apócope, procedemento fonético que nos últimos anos está suplantando os demais.

A secuencia cronolóxica que se seguiu aquí foi a de distinguir tres períodos, coincidentes coas tres etapas fundamentais que distinguimos na antroponimia galega: unha primeira de conformación, coincidente coa Idade Media; outra correspondente aos Séculos Escuros e que chega a finais do século XX, caracterizada pola intrusión do castelán e a forte influencia da Igrexa católica; e, finalmente,a terceira, que comeza a finais do séc. XX, tralo remate do franquismo, o cambio das leis e as mudanzas das condicións sociolóxicas. Desta maneira veranse as primeiras (e escasas) mostras de hipocorísticos nos primeiros textos; comprobarase que os procedementos de formación, xunto co sistema nominal, permaneceron case invariables nos séculos seguintes, e, finalmente, que non é ata final deste período (s. XX) cando se deron maiores cambios na elección de nomes e, por ende, tamén dos hipocorísticos.

\section{As primeiras atestacións: os alcumes na Idade Media}

Se ao principio apuntaba os problemas da recolleita actual dos hipocorísticos, estes problemas aumentan, loxicamente, se o campo de estudo é a lingua medieval. Nestes casos, o único que podemos consignar é a constitución morfolóxica, é dicir, a presenza ou non de sufixos diminutivos. Xa teño dito (Boullón 1999: 69-71), que as máis antigas atestacións de segundos nomes, introducidos pola fórmula latina cognomento, estaban en bastantes ocasións constituídas por hipocorísticos, que se formaban de maneira semellante aos actuais: por aférese (exemplos a, b, c), sufixación (d, e), coa combinación de varios destes procedementos (f, g), con sufixos diminutivos a partir de nomes diferentes $(h, i, j)$, ou por reduplicacións dunha sílaba $(\mathrm{k})$; este parece ser o caso de Pepe, antigo nome medieval que aquí parece funcionar como hipocorístico de Pedro en dúas ocasións $(1, \mathrm{~m})$.

a) Geldemiro cognomento Mira a.918 TSobrado I 124,

b) Segesinda cognomento Sinda $=$ Segesinda cognomento Sindina a.932 TCelanova 103

Púxoseme farruco e tiven que ameazalo. CF. valente. 2. Que se aferra con enerxía e empeño a unha idea ou a unha maneira de actuar, persistindo nesa actitude. Como se poña farruca non hai quen lle faga cambiar de idea. CF. cazurro, obstinado (máis culto), teimoso, teimudo, testán, testudo. 3. Que se mantén áxil, con saúde e con bo aspecto [persoa], mesmo a pesar da idade. Está moi farruco para os anos que ten. SIN. rufo. 4. Cheo de fachenda e con moita satisfacción de si mesmo. Puxo o seu mellor traxe e saíu á rúa todo farruco. SIN. rufo" (Dicionario da RAG, dispoñible en http://www.edu.xunta.es/diccionarios). 
c) Belfonsus cognomento Fonsu a.963 TSobrado I 119

d) Mariam Cipriani Mariolam cognomento a.[1152] TSobrado I

e) Petrus Stephani dictus Perroch a.1202 TSobrado II 409

f) Isilo cognomento Sisina a.803 TSobrado I 110

g) Marinam Froile de Balone cognomento Riolam a.1220 TSobrado II 358

h) Uistragildus cognomento Gotinus a.842 TSobrado I 110

i) Guduildi cognomento Nunina a.905 TSobrado I 98

j) Clixovara cognomento Gotina a.963 TCelanova 140

k) Teodildi cognomento Titi a.937 TCelanova 130

l) Pepi $=$ Petrus cognomento Pepi a.953 TCelanova 77

m) Petrus cognomento Pepi Arias [notario] a.991 TCelanova 28

Cómpre ter en conta, no entanto, unha prevención sobre o valor destes sufixos, pois non temos constancia absoluta de que fosen afectivos. De feito, o sufixo -inus era usado, en época latina, con valor patronímico, e este valor aínda parece estar en uso nalgúns dos nosos exemplos medievais, tal como se ve en Palumbina filia Pelagii Palumbo (a.1190 TSobrado I 217). En todo caso, dado que a partir do século XI se xeneralizou o uso do patronímico, expresado ben polos sufixos propios (con fasquía latinizante primeiro, $-i z$, - $i c i$, -izi, -it, e finalmente coas formas romances -ez e -es), o sufixo -inal-us e outros máis (como -ula/-us, -ella/-us, -olal-us, -ita/-us), foron habilitados para a formación de numerosos nomes de orixe case sempre latina. Nestes nomes, lexicalizados xa co sufixo integrado, xa non se pode advertir unha función hipocorística clara. Son formas como Abbatinus, Guntinus, Avolinus, Seniorinus, Argentina, Godina, Flammula, Bonellus, Domnella, Auriolus, Pelagiolus, Piniolus, Raiola, Liliola, Grasiola, Bellita, Nunnita, Domnitus, Mellitus (máis exemplos en Boullón 1999: 88-90). Na baixa Idade Media isto xa non se dá: a maior parte destes nomes mencionados deixan de estar de moda, e os nomes femininos que presentan a terminación -iña non o portan como sufixo, senón por evolución fonética: Mariña $(<\text { MARINA) })^{7}$ Esteveíña ( $<$ STEPHANIA), Cataliña (< EKATERINA: vid. nota 3) e Martiña (< MARTINA).

A devandita explicitación dos "cognomentos" case desapareceu dos documentos ao xeneralizárense os segundos nomes, na súa maior parte patronímicos. A partir daquela, apareceu a forma romance dito para ir seguida, normalmente, de alcumes, cun uso frecuente de sufixos diminutivos, habitualmente a partir de bases léxicas. O máis abundante, é, como é previsible, -iñalo, do que indico algúns exemplos ordenados cronoloxicamente:

7 A explicación tradicional deste nome é a extensión do culto a santa Mariña de Antioquía, por volta do séc. VII (Piel 1949: 347), que deu lugar a 53 referencias toponímicas en Galicia, das que 12 son parroquias (Nomenclátor de Galicia 2003). Outra hipótese faino hipocorístico de María. 
Maria $P e q<u e>$ nina a.1326 DocUnivSantiago $71=$ Maria $\mathrm{P}<\mathrm{e}>\mathrm{l}<\mathrm{a}>\mathrm{s}$ dita Peq<ue $>$ nina de Bemuiure a.1330 DocUnivSantiago 104

$\mathrm{P}<\mathrm{er}>\mathrm{o}$ Mõteyriño de Pumar de Rrioo a.1341(or.) DocNoia $15 \mathrm{n}^{\circ} 2$

$\mathrm{G}<$ oçalv>o Caluino fferr<eyr $>0$ a.1372(1414-1500) TBieitoSantiago 36

Afonso Vidal dito Fieytino a.1394(or.) DocNoia $29 n^{\circ} 12$

Rroy Rroxiño a.1446(or.) TBieitoSantiago 70

Jua4 Frãquiño a.1448(or.) CDRamirás 572

Johan Patiño a.1454 DocDevOurense 2, 62

Martiño Menyño a.1454 DocDevOurense 2, 61

Rroy Mouriño de S<an> Tome a.1457 LNotasRianxo 773

Hai tamén outros alcumes nos que se parece recoñecer outros sufixos diminutivos:

suf. -ela/o: Eluyra Mourela a.1378 DocUnivSantiago 252; Costança Martina Minanguela a.1429 CDFerreira 194; Ynes Rugela a.1434 PadrónsOurenseXV 48, Fernan Mourelo a.1473 CDMondoñedo 384

suf. -ucha: Garcia Marucha a.1187 TSamos 370

suf. -ete: Petr $<$ us $>\mathrm{P}<$ e $>1<$ a $>$ gij $\mathrm{d}<\mathrm{i}>\mathrm{ct}<$ us $>$ Rebolete a.1326 DocUnivSantiago 71

En poucos casos este sufixo está engadido a nomes propios situados en segundo lugar na cadea onomástica:

Domingo Aluarino home de Joh<á>n Eanes de Padrõ a.1342(or.) DocNoia $17 \mathrm{n}^{\circ} 4$

Pero $S<$ an>tiagujño a.1457 LNotasRianxo 385

No seu traballo sobre o patronímico na baixa Idade Media, Diéguez (2000: 655) recolleu máis formas hipocorísticas, tiradas en parte de testamentos, e referidas a criados que son citados con esas formas diminutivas:

Aldara: Aldariña a.[1480] PadrónsOurense 89

Afonso: Afonsino (1375 GH 81); Afonsin a.1427 DocUnivSantiago 305, Alfonsjno a.1457 LNotasRianxo 648.

Albertina de Canbeiro (1436 FU 305), Albertina (1402 FU 266); Albertinna (1433 FU 288); Albertina (1433 FU 289) [Non creo que sexan formas diminutivas, como tamén dubida Diéguez, porque o feminino Alberta non se

8 Escólmoas e ordénoas doutra forma, engadindo algúns exemplos máis (que se distinguen polo tipo de citación bibliográfica), e resaltando os sufixos en cursiva a primeira vez que aparecen. Os textos entre parénteses angulares $(<>)$ indican cursiva no orixinal. 
documenta na Idade Media, ao contrario ca Alberte, o que parece indicar que aquí o sufixo emprégase para formar a forma feminina].

Antonio: Antoninho Martinez clerigo (1374 TUI 89). "que provavelmente não terá sido verdadeiro diminutivo, mas a forma derivada de ANTONINUs".

Bernaldo: manifico señor don $\mathrm{V}<$ er $>$ naldino $\mathrm{P}<$ ere $>\mathrm{Z}$ Sarmẽto cõde de Riba d'Abja a.1499 CDMaia 178.

Domingos: Domygos Estevez dicto Myngachos (1422 C.H.P., Chelas 189).

Fernando: Fernandillo (1287 VF1 29); Fernandino (1335 OS3 1578); Fernandijño a.1345(or.) DocNoia 18n5, Fernandyno Ferreiro (1385 FU 250); Fernandino do Paaço (1402 FU 266).

Gomez: Gomeziño de Leiro (1506 MF 11).

Gonçaluo: Gonçaluino a.1361 CDRibadavia 69, Gonçelino Roiz (1470 VF2 $353)$.

James: Jamete raçoeiro de Mendonedo (1326 GH 71).

Johan: Joanino Dogresso a.1269 CDMaia 182; Jaanino clerigo de Toruẽo a.1281 CDMaia 134, Johanino, ffillo de Ffernã Ioh<an>es a.1281 CDMaia 133; Johãniño, o alfagime a.1310 CDMaia 85; Joh<a>njno pai de Johan de Vilachãã a.1332 DocUnivSantiago 123.

Lopo: Lopillo [irmán de Gil e Jacome, fillos de Vasco Lopes de Burgos e de Moor Peres], 1442 FU 322).

Maria: Mariam Cipriani cognomento Mariolam (a.[1152] TSobrado I); casam de Mariola (1221 RS 27); Marica Gomez (1435 DH1 10); Maricas do Barreyro (1435 DH1 10); Maricas (1434 FU 296).

Maior: Mayoriña (1427 FU 281).

Mendo: Meendiño (o trobador).

Paulo: Paulucho (1330 CM 779, 1333 CM 817) = Paulucum [reitor de $S^{\mathrm{a}}$ María de Viveiro] a. 1305 CDMondoñedo 98 = Paulucho a.1331 CDMondoñedo 131 = Paulucho coengo da yglesia de Mendonedo a.1333 CDMondoñedo 133.

Pedro: Gunzalvo Perrot ${ }^{9}$ a.[942-977] TCelanova 226, Diego Perrote a. 1329 CDMondoñedo 128, Pedrote (1424 VL 179), Pedruchi ${ }^{10}$ petrarium a.[1152] TSobrado II 130, don Pedrol (1212 RA 7), Pelagio Martini Pedrol (1250 RA 78), Pedrol Alfonsi (1253 RA 102), Pedrellyno da Grova (1278 OS2 1124);

9 Esta forma, documentada só nos tombos de Celanova e Sobrado (véxase Boullón 1999: 361), podería ser derivado de Pierre e proceder dunha forma do leste (Francia ou Cataluña), coma no fr. Perrot e Pierrot. Que ten relación con Pedro parece corroboralo a seguinte atestación: Petrus Stephani dictus Perroch a.1202 TSobrado II 409.

${ }^{10}$ Con respecto a esta forma hai varias hipóteses, desde ser o antecedente do hipocorístico Perucho, ata vir dun radical prerromano (véxase Boullón 1999: 350). 
Pedrucho d-Alenparte (1279 OS2 1138); Pedrocho d-Alenparte (1279 OS2 1139); Pedrelinno do burgo (1287 Sobrado de Trives 15); Juan Perez llamado Pedruxo (1298 CM 393); Perucho criado de fernã sanches (?) (1479 DH1 11).

Sabastian: Bastian d'Ayaço, notario da Pobra do Deán de Santiago (que asina o documento como Sabastian d'Ayasio; doc. inédito de 1482, procedente do Arquivo Histórico Diocesano de Santiago).

Neste traballo ofrécense tamén outros datos interesantes sobre as motivacións do uso dos diminutivos, como na seguinte cita do Livro de Linhagens (Diéguez 2000: 656):

Este Rui Diaz d'Urroo, que ja dissemos, houve ũa filha de gaança em ũa molher filha d'algo, e havia nome dona Tareija Rodriguez, e chamarom-lhe por sobrenome, quando era moça, Tereijinha, porque bailava bem (LL 44 R 3).

Ou a cadea onomástica Pedro Perez dicto Pedrinho (1317 BM 20), localizada nun documento portugués (do Baixo Mondego), onde se ve claramente a substitución do nome no uso real polo seu diminutivo. Tamén achega o cambio nominal de Lupi Petri de Costa (1263 SCL 111), no mosteiro de San Clodio do Ribeiro, que aparece primeiramente nomeado como Lupillus de Costa (1214 SCL 25), o seu diminutivo latinizado, e mais tarde como Lupillino de Costa (1240 SCL 51) (Diéguez 2000: 142). Neste caso, prescíndese do patronímico, demasiado corrente para ser identificativo (Petri), e recórrese aos diminutivos cos que debía ser coñecido no seu contorno familiar, así como ao designativo toponímico.

En definitiva, os datos que se poden inferir do sistema denominativo medieval a través dos documentos parecen apuntar a unha situación semellante á de hoxe: as formas hipocorísticas, afectivas, usábanse na intimidade familiar ou en situacións informais e poucas veces se reflectían nos rexistros escritos, a non ser que supuxesen unha identificación máis útil có propio nome sen os sufixos.

\section{Dos Séculos Escuros ao XIX}

Como é ben sabido, a partir do séc. XVI desapareceu a lingua galega dos textos escritos. Iso non significa que os nomes persoais desaparecesen tamén da lingua oral, porque, se ben a castelanización dos documentos foi progresiva e case sistemática, na lingua falada a situación non foi a mesma. Sabémolo, naturalmente, por testemuños indirectos, pois, desde que no Concilio de Trento (1545) se dispuxo o rexistro sistemático dos nacidos, a lingua en que o fixo a Igrexa católica foi o castelán ${ }^{11}$, e así mesmo ocorreu nos catastros posteriores, feitos xa pola administración

11 Véxase como exemplo abondo representantivo o exhaustivo estudo feito por Lema (2006) para os nacidos na parroquia de Berdoias (Vimianzo-Co), desde 1607 ao ano 2000. 
civil (pensemos nos Catastros de Ensenada, por exemplo, de finais do XVII). No entanto, os testemuños epistolares revélannos outra situación: na correspondencia privada do conde do Gondomar (1605) figuran as formas Joaniña e mais Janiña (Álvarez Blanco / Montederramo 2004); tamén nas cartas que o Padre Isla lle mandaba á súa irmá, a ilustrada María Francisca de Isla (entre 1755 e 1781), chamáballe, entre outras formas cariñosas, Marica ou Maruxiña. E isto no que respecta ás clases superiores, porque as populares vivían a cotío (agás nos momentos do bautizo, do casamento ou do funeral) cunha forma galega, moitas veces coincidente cun hipocorístico. Recórdese, por exemplo, os nomes que Sarmiento lles daba aos protagonistas do seu Coloquio $^{12}$, que constan sempre dunha forma galega e mais un designativo, habitualmente toponímico:

\begin{tabular}{|c|c|}
\hline $\begin{array}{l}\text { Perucho dos Merlos, } \\
\text { Maruxa das Rulas, } \\
\text { Xepiño da Fonte, } \\
\text { Minguiña do Rego. }\end{array}$ & $\begin{array}{l}\text { Roque de Beluso, } \\
\text { Bastián do Castelo, } \\
\text { Jhan de Figueirido, } \\
\text { Mingos do Penedo. }\end{array}$ \\
\hline $\begin{array}{l}\text { Antón de Domayo } \\
\text { Mamed de Salcedo } \\
\text { Albertos de Coiro } \\
\text { Macías de Hermelo }\end{array}$ & $\begin{array}{l}\text { Lucía da Esculca, } \\
\text { Thereixa do Cerro, } \\
\text { Farruca da Braña, } \\
\text { Marta dos Rexelos }\end{array}$ \\
\hline $\begin{array}{l}\text { Martiño dos Cobres, } \\
\text { Bartolo do Teso, } \\
\text { Bieito d'Ardán, } \\
\text { Bras de Montezelo, }\end{array}$ & $\begin{array}{l}\text { Andrea da Chauza, } \\
\text { Thomasa d'Outeyro } \\
\text { Catuxa do Mato, } \\
\text { Mariña a do Cego. }\end{array}$ \\
\hline
\end{tabular}

Ademais, para entrever a situación real cómpre ter en conta o testemuño da literatura, que nos informará a este respecto de forma máis real cós listados oficiais. No seu estudo sobre os nomes persoais en Majina ou a filla espúrea, Fernández Salgado (no prelo) comenta que

a forma galega do antropónimo era a comunmente utilizada entre os veciños da aldea; non obstante, a forma castelá era a que seguramente figuraba na súa partida de bautismo e a que se empregaba nos documentos oficiais (véxase o caso das cartas). Deste xeito, o nome patrimonial galego (Caitán ou Bieito) viñan sendo entendidos e empregados como unha especie de hipocorístico ou de forma familiar. De feito é significativo que tanto as de Sancti-Petri como Salvio cando traducen os nomes de Cayetano ou Benito os fan acompañar

\footnotetext{
${ }^{12}$ Cito pola edición facsímile (Sarmiento [1746]), modernizando a acentuación.
} 
sempre de "señor", porque á fin e ó cabo cómpre manter o trato cortés e nese caso non cabe o hipocorístico.

Se se comparan os hipocorísticos deste período e os do século XX, verase que coinciden en boa medida no que se refire ao tipo de procedementos (véxase o apéndice), excepto en dous aspectos. En primeiro lugar, as diferenzas derivadas da frecuencia dos nomes de que proceden, dado que, en xeral, os nomes máis frecuentes son os que máis hipocorísticos presentan. Por exemplo, Domingo(s), o $\mathrm{n}^{\circ} 6$ no ránking no XVII ${ }^{13}$, presenta os hipocorísticos Mingo, Mingos, Mingote, Mingacho e mesmo o diminutivo Minguiño; en contraste, no século XX, en que baixou ao posto $\mathrm{n}^{\circ}$ 61, xa só aparecen nunha fonte escrita as dúas primeiras; o feminino, que baixou desde o posto $7^{\circ}$ ao 324, presentaba os hipocorísticos Minga e Mingota e mailas diminutivas Dominguiña e Minguiña no XVII, mentres que no XX xa non atopamos ningunha. E Bartolomeu, que ocupa o posto 24 no ránking dos nomes máis frecuentes nestes séculos e ten os hipocorísticos Bértolo, Bartolo, Bartoldo, no XX baixou ao posto 823 , só ten as dúas primeiras formas das citadas, e esas claramente en regresión.

En segundo lugar, hai algúns nomes, de parecida frecuencia, que só parcialmente coinciden nos hipocorísticos. O caso de Antonio é bastante curioso: nese período ocupa o $\mathrm{n}^{\circ} 9$, é dicir, bastante alto. No entanto, nas fontes escritas só se rexistra a forma acurtada Antón (que se identificaba coa galega: de feito, nos lugares oficiais como poden ser os Catastros non se rexistra nunca), mentres que no do séc. XX, onde consta coma o $3^{\circ}$ en orde de frecuencia, ten 13 hipocorísticos distintos. $\mathrm{O}$ mesmo ocorre cos de Xosefa (que está case no mesmo posto nos dous períodos, $13^{\circ}$ e $14^{\circ}$ ): de Pepa pásase a 13 formas máis. No que lle atinxe ao masculino, Xosé, ocorre que os hipocorísticos son distintos: documéntase desde o XVIII Chisepe e Xepe (co diminutivo Xepiño), onde está presente o - $p$ final etimolóxico, a partir do cal se formaría, por reduplicación, o estendidísimo Pepe (véxase infra, nota 17). Ou o caso dos de Xoaquín, que, a pesar de baixar en frecuencia (do $11^{\circ}$ ao 54 ), aumentou no número de hipocorísticos.

\section{5. $O$ corpus do séc. $X X$}

A relación dos hipocorísticos compilada (reproducida en anexo) que, polas peculiaridades anteditas, non poderá ser exhaustiva, pero creo que si abondo representativa, inclúe preto de 430 formas, correspondentes a outros tantos nomes; non todas elas son distintas, porque unha mesma forma pode corresponder a nomes

13 O ránking do séc. XVIII está realizado a partir dos datos do Catastro de Ensenada correspondentes a Santiago, Coruña, Tui e Cabanas. Con respecto á lista do século XX, os datos proceden do Censo de 2001, do INE. Véxase unha lista comparativa dos 20 nomes máis frecuentes no punto 7. 
diferentes; e, á inversa, nalgúns dos nomes concéntrase unha gran variedade de formas (tales como Manuel, Francisco, Antón, Carme, María, XosélXosefa). A razón é, obviamente, a gran frecuencia que eses nomes tiveron, que forzou os seus portadores a usaren formas diferentes para evitar a homonimia.

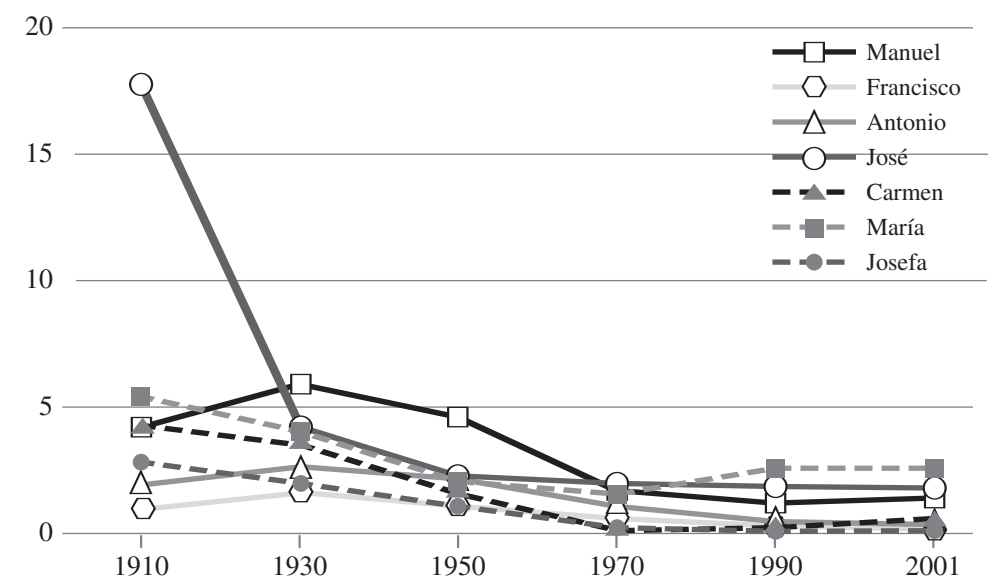

Gráfico 1. Vitalidade dos nomes con máis hipocorísticos no séc. XX (en porcentaxe).

Segundo os datos do censo do Instituto Nacional de Estatística (Madrid) correspondente a 2001, todos estes nomes están en regresión desde principios do século XX (salvo Manuel, que acadou o seu apoxeo en torno á metade do século), aínda que algúns deles, como María ou Manuel, experimentan un lixeiro repunte no primeiro ano do XXI, ou quizais sería máis axustado dicir un parón no descenso. Hoxe en día as tendencias onomásticas son distintas: hai novos nomes e moita maior variabilidade, isto é, menos concentración. Por iso, a concentración dos hipocorísticos por nome diminuíu, e tamén o tipo de procedementos empregado.

\subsection{Características xerais do corpus}

No que respecta ao número de sílabas e ao tipo de acentuación, dicía Boyd Bowman (1955: 346), referíndose ao español, que calquera que sexa o número de sílabas ou a acentuación do nome pleno, as formas hipocorísticas son case sempre de dúas sílabas e de acentuación grave. Non é exactamente así no caso do galego, aínda que é certo que os bisílabos predominan: a lonxitude máis habitual (nun $60 \%$ ) é de dúas sílabas, algo máis ca nos nomes comúns (o que non é de estrañar porque, como veremos máis adiante, o acurtamento de sons é un dos procedementos favoritos para a súa formación), pero os trisílabos teñen unha presenza numérica importante (un 36\%). Da mesma maneira que ocorre cos nomes propios 
(Regueira 2007: 242), hai diferenzas xenéricas: os hipocorísticos femininos presentan máis proporción de nomes trisílabos cós dos homes; estes últimos aproxímanse máis á estrutura xeral dos substantivos na lingua común: a principal diferenza entre eles é unha maior proporción de nomes bisílabos nos hipocorísticos masculinos (65\% fronte a $52 \%)$.
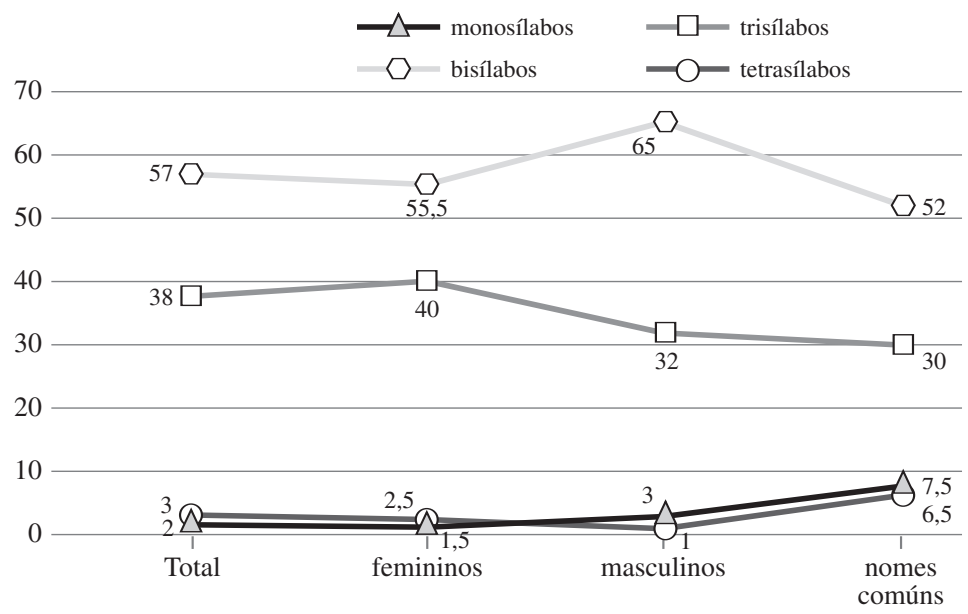

Gráfico 2. Lonxitude dos hipocorísticos (porcentaxe)

Atendendo á acentuación, son maioritariamente graves (89\%); os minoritarios agudos son monosílabos (Che, Quin, Xan, Nes, Chon, Chus), proceden de nomes así mesmo agudos (Colás, Vitín, Xaquín), portan o sufixo dialectal -ín no canto de -iño (Pepín), ou ben están formados por reduplicación (Cheché, Teté, Loló, Totó) ou por síncope de nomes compostos (Anabel, Mariló, Marisé, Xelís, Chelís, Maribel, Marité); estes dous últimos tipos parecen tamén procedementos máis modernos con respecto aos tradicionais. E, a diferenza dos nomes comúns e dos antropónimos, só se rexistra un esdrúxulo, Bértolo, o que significa un 0,2\% (a porcentaxe respectiva neses grupos de referencia é dun 4\% e 5\%: véxase Regueira 2006: 243).

En canto á distribución xenérica, é practicamente equitativa (48,5\% os femininos, $51,5 \%$ os masculinos), o que parece discordar cos datos portugueses: "o uso actual [refírese a principios do XX] de hipocoristicos em pessoas adultas é todavia mais freqüente em mulheres do que em homes, porque o mimo que na primeira infancia era comum aos dois sexos ... desapareceu essencialmente no homem, depois que este se tornou adulto; só a mulher permanece terna e ameninada!" (Leite de Vasconcelos 1928: 492). O último comentario do sabio portugués está sen dúbida fóra do noso tempo, pero á parte da valoración, e polos datos que temos, non me 
atrevería eu a asegurar que no século XX houbese en Galicia maior proporción de hipocorísticos femininos ca masculinos. Claro que, en realidade, temos menos datos de mulleres ca de homes, tradicionalmente, pois en tódalas instancias escritas estiveron infrarrepresentadas. O que mostran os datos aquí compilados é que o número de hipocorísticos é semellante para ámbolos sexos, cunha lixeira vantaxe para os homes.

Por outro lado, hai que indicar que a deturpación castelanizadora dos nomes propios chegou tamén, aínda que en pequena medida, aos hipocorísticos. Trátase fundamentalmente de formas que proceden de nomes que tiñan /x/ na súa forma oficial, castelanizada, evidentemente: Genucha < Eugenia, Geluco, Gelucho < Ángel/Eulogio, Gina < Regina. Nestes exemplos vese claramente que o que se fixo foi adaptar dous sons semellantes, o fricativo velar xordo castelán ao da gheada; polo demais, séguense os procedementos derivativos habituais. De feito, hai bases léxicas castelás ás que se lles aplica, sen máis, os procedementos morfolóxicos e fonéticos galegos, como en Joseíño, Josiño ou Juansiño, neste último exemplo co interfixo habitual nos diminutivo rematado sen nasal, e pronunciado con seseo. Do sufixo -ito fálase especificamente máis adiante. En Ligucho < Eligio, parece haber unha mostra de gueada (a non ser que se pronuncie con gheada, asemellándose asî máis ao nome castelán do que procede), como tamén hai mostras de gheada en Justo < Agustín.

Hai que considerar, de todos modos, que é moi difícil cuantificar a influencia dos hipocorísticos de orixe castelá no caso daqueles dos que non hai evidencias fonéticas de selo. É dicir, formas como Chuchú, Chus, Quique, Teté, non parecen axustarse ao sistema tradicional de formación en galego (como se detalla no capítulo seguinte), pero tampouco non presentan características fonéticas ou morfolóxicas alleas. Por tanto, coido que neste aspecto só se podería facer unha estimación aproximativa.

\subsection{Procedementos de formación}

Os traballos previos referidos á formación dos hipocorísticos en portugués (Leite de Vasconcelos 1926: 479-491), e en castelán (Boyd-Bowman 1955, Buesa 1988) coinciden en advertir diversas formas de redución de sílabas, o redobro ou reduplicación de sílabas e a palatalización de certos sons, en proporcións disimilares (por exemplo, o redobro parece moito máis frecuente en portugués, e a palatalización en español). En xeral, a maior parte dos procedementos proceden da linguaxe infantil, e isto implica tamén unha certa asistematicidade. Por exemplo, estes principios poden ser aplicados a nomes distintos, de maneira que o mesmo hipocorísticos pode corresponder a nomes cun parecido fonético distante, como Lucho (de nomes que conteñen l: Emilio, Rafael, Anxelo, Lois), Chicha (de nomes que teñen í: Elisa, María, Rosalía, ou non, como Carme ou Concepción), Nuchol-a (de 
nomes con $n$ na sílaba final, como Marcelino/-a, Xoana), Dora (de nomes que inclúen esta secuencia fonética, como Dorotea, Adoración, Teodora), Tino (acurtamento de nomes rematados así, como Constantino ou Florentino). E outros, os máis expresivos, xa constitúen denominacións hipocorísticas autónomas, que se recoñecen como tales e valen para calquera nome: Pitusa (de Pilar ou de Xosefa), Chicho (de Narciso, Ricardo, Román, Perfecto), Cholo (de Andrés, Eliseu, Henrique, Manuel, Gonzalo, Xosé Luís).

Os procedementos de formación dos hipocorísticos adoitan presentarse combinados: aférese + sufixo, apócope + morfema xenérico, palatalizacións etc. En realidade, só un $26 \%$ dos analizados presentan un único fenómeno fonético ou morfolóxico. Tendo isto en conta, aludirei aos máis frecuentes: a supresión de sons, principalmente a aférese $(57 \%)$, e en moito menor grao a apócope $(9 \%)$ e a síncope (9\%), por veces en combinación. Despois, a adxunción de sufixos (43\%), case todos eles propiamente antroponímicos. En terceiro lugar, o uso de sons palatais, que afecta o 38\% das formas, e que se dá (especialmente con $/ \mathrm{t} /$ ), moitas veces en sufixos (o 46,5\% deles lévanos), pero tamén no $17 \%$ das formas non sufixadas. Por último, outros procedementos constátanse con porcentaxes inferiores ao $15 \%$ (monotongacións, reduplicacións, adxunción dun morfema xenérico e algún outro).

\subsubsection{Supresión de sons}

Os tres procesos de recorte de sons afectan de maneira diversa ás raíces dos hipocorísticos, e en conxunto fano nun $82 \%$. Iso non significa que a lonxitude final do hipocorístico sexa menor na mesma proporción cós nomes dos que derivan, pois estes procesos están en moitas ocasión combinados co agregado de sufixos. Así, os que presentan diminución con respecto á raíz son maioría, un 64\%, pero hai uns cuantos que a incrementan (8\%), e os restantes mantéñense coa mesma lonxitude $(28 \%)$.

Coma en castelán ou catalán (véxase Garcia i Osuna 2003: 362), o procedemento da aférese da sílaba inicial (ou de máis dunha) é o maioritario dos que supón acurtamento silábico, aínda que só o $11 \%$ o presentan como exclusivo (Nando, Fonso, Sefa...); na maior parte dos casos está ligado a outro, como pode ser a inclusión do ch (Chefa < Xosefa, Chon < Asunción), o engadido dun sufixo (Ducho < Cándido, Xeluca $<$ Anxela, Mela $<$ Carmela $<$ Carme) ou outros. En ocasións só resta a sílaba tónica do nome orixinal (Tocho $<$ Antonio), ou a final (Tocho $<$ Benito), e ao engadirlle un sufixo pode subsistir unicamente a consoante, coma en Tuchalo, Luchalo (<Emilialo ou Rafael). Téñase en conta que en antroponimia é especialmente frecuente o que en derivación se chama substitución de prefixo ou truncamento (así en Matuca < Matilde, Educho < Eduardo, Vitolo < Vítor), o que no noso corpus ocorre nun 8,5\%; agora ben, en ocasións, o segmento substituído non é un 
sufixo, senón outra secuencia non exactamente recoñecible como tal (como en Concepción < Concha, Mercedes < Merche), aínda que recorde foneticamente aos sufixos: "La charge sémantique réduite du NP semble permettre la réduction du corps phonique dans une mesure qui, pour un lexème, mettrait en danger l'intelligibilité" (Weinhold 2007: 117).

O acurtamento de sons é o procedemento preferido polos nomes compostos, e entre eles o máis frecuente é a síncope: de considerar os dous nomes como unha entidade fonética, redúcese o final de un mailo principio do outro (Maloles < María Dolores, Maribel < María Isabel), por veces coa única conservación da sílaba tónica: Mariló < María Dolores. A apócope é numericamente semellante (Encarna < Encarnación, Reme $<$ Remedios), e pode incluír a presenza dun morfema xenérico que antes non había (Xanxo < Xan Xosé, PuralPorfica $<$ Purificación).

\subsubsection{Adxunción de sufixos}

Os sufixos que aparecen na formación dos hipocorísticos son os diminutivos, usados co seu propio valor (pois aplícanse, en principio, aos nenos pequenos), e cunha forte carga afectiva, matices ámbolos dous que comparten na lingua xeral, se ben nos antropónimos están desprovistos da carga depreciativa que si teñen na lingua común. E non sendo o sufixo -iño, os outros son practicamente improdutivos (Freixeiro Mato 1996: 50); o único ámbito en que se seguen mostrando autenticamente rendibles é, xustamente, no da onomástica.

Os sufixos máis frecuentes son os que teñen $u$ como vogal tónica (presente no 56\% das formas sufixadas, repartidos entre os sufixos -uchalo, -ucalo, -uxa, -usa, -ulo), seguidos a moita distancia dos que teñen $i$ (21\%: -iñalo, -italo, ica), o (15\%: -ochalo, -olo, -ocas, -olas, -ote), e (8\%: -echo, -eco, -ela) e só dous con a (-ach-o). A frecuencia dos sufixos en $u$ posiblemente se deba a que esta é a vogal menos frecuente na lingua común (Regueira 1989: 127-128), a mesma razón pola que tamén abundan os sufixos coa consoante / $\mathrm{t} /$, que supoñen o $46 \%$ do total. Como xa observou Buesa (1988: 1619) para o español, ao estaren moi escasamente representados na escala de frecuencias, estes sons "adquieren un valor intencional marcadamente expresivo o fonosimbólico". En principio, os sufixos con $u$ na lingua común teñen un valor pexorativo (Alonso Núñez 2000: 149), pero aplicados aos nomes adquiren un matiz diminutivo e afectivo.

Amais da clasificación por vogal, podemos ver tamén algunhas series consonánticas: -ach-/-ech-/-och-/-uch-, -ec-/-oc-/-uc-, -el-/-ol-; en realidade, tense dito que un modo de multiplicar os sufixos é alterar a súa vogal tónica xerando gamas vocálicas (Michaëlis de Vasconcelos 1946: 77-78, apud Alonso Núñez 2000: 151). Por iso a orixe etimolóxica de moitos deles non está clara, pois, amais da súa procedencia case sempre latina, puideron ir sendo xerados por este procedemento. Por 
último, é remarcable a combinación de varios sufixos: Pepitiña, Maruxela, Lucha (< Carmelucha) e a posibilidade de xuntar distintos sufixos ao mesmo nome: Xoaquina $>$ Nocha, Nucha.

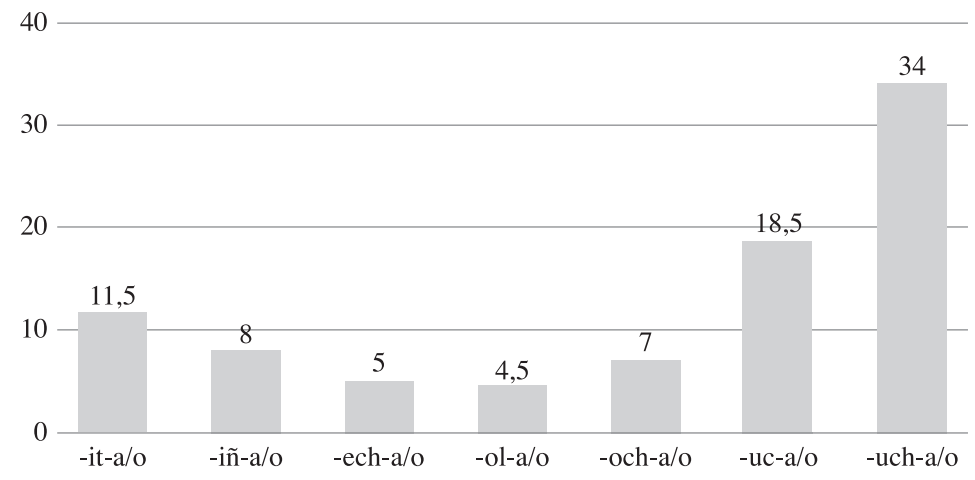

Gráfico 3. Porcentaxe de uso dos principais sufixos hipocorísticos

5.2.2.1. - uch-alo (< lat. -usco + ULU) é o máis empregado dos sufixos, pois aparece en 62 hipocorísticos (o $34 \%$ de tódalas formas con sufixo). Na lingua común parece ser empregado especificamente con valor pexorativo (leirucha, casucha, tenducha), segundo García de Diego (apud Freixeiro Mato 1996: 55), pero nos nomes é fundamentalmente afectivo: Carmucha, Luchalo, Nuchalo, Tucho $(<$ Antonio), Pacucho (< Paco), Carducho ou Ricucho (< Ricardo), Filucha $(<$ Filomena), etc. Hai antecedentes medievais: Pedrucho en 1279, Paulucho en 1305, Perucho en 1479, e tal vez antes, xa no XII (véxase supra, cap. 3 e nota 10). En catalán, -utxo (Perutxo) é sufixo considerado variante de - ussa e -assa, tamén aumentativo e despectivo (Garcia i Osuna 2003: 336).

5.2.2.2. -uc-alo ("probábel var. de -ico" para Ferreiro 1997: 191) está en 34 hipocorísticos, máis en femininos (Beluca < Isabel, Teruca, Uca $<$ Maúca $<$ María, Miluca, Lenuca < Helena), ca nos masculinos (Farruco, Fuco, Vituco < Vítor ou Vicente; en Chuco < Francisco pode haber unha metátese a partir de -ucho, a través de Franciscucho), nunha proporción de 24 a 10. Na lingua común rexístrase como bastante rendible, pois aparece, normalmente con valor despectivo, en baratuco, casuco, delgaduco, mulleruca, fachuco ou tamén afectivo, coma tal, en festuca, feituco (véxase Freixeiro Mato 1996: 56).

5.2.2.3.- $u x$ - $a$ ("podería constituír unha variación de -uco con influxo de -exo [do esp. -ejo]" Ferreiro 1997: 191) rexístrase en dous nomes femininos, de moi alta 
rendibilidade (Maruxa e un seu derivado, Maruxela, e en Catuxa) e mais en Peruxo (en Xuxo non hai sufixo, pois é palatalización do $s$ orixinario). Estes exemplos femininos son os citados nas gramáticas que tratan o sufixo, onde se lle dá valor diminutivo, como en cabuxa, babuxa 'néboa' (en ambos os dous casos xa lexicalizado), airuxo, e tamén en bases adxectivas: branduxo, calmuxo, pequenuxo (véxase Freixeiro Mato 1996: 57). Porén, a súa produtividade moderna ten sido posta en cuestión (Alonso Núñez 2000: 151). Para o antecedente medieval citado no cap. 3, Pedruxo (a.1298), hai problemas de transmisión textual, porque o testemuño está tomado dunha rexesta feita en castelán a partir non dun documento orixinal, senón dun tombo (véxase $\mathrm{CM}$, nas fontes medievais).

5.2.2.4. $-u s-a$. Esta terminación non a atopamos nas descricións gramaticais galegas. No corpus manexado aparece só en Matusa $(<$ Matilde) e mais en Pitusa, correspondendo a dous nomes distintos, Pilar e Josefa; aquí en realidade é difícil decidir se se trata realmente dun sufixo, porque, se ben nun caso hai unha certa similitude fonética (Pilar), no outro semella totalmente arbitrario, porque con Josefa apenas hai ningún tipo de concomitancia. En catalán, -ussa

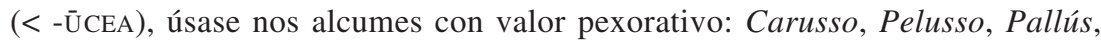
Pallusa, Parrús, Parrusa (Garcia i Osuna 335).

5.2.2.5. -ul-o: só en Panchulo (< Pancho < Francisco) e mais en Martula. Tampouco se rexistra nos repertorios de sufixos; no primeiro caso pode non ser máis ca un xogo co adxectivo "chulo", que cadra ben coa base léxica e recorda aos sufixos con vogal tónica en $u$, pero no segundo é claramente un sufixo, a partir de Marta.

5.2.2.6. -och-a/o: interpretado como variante alomórfica de -echo (véxase infra) e en certa medida de -ucho (véxase Ferreiro 1997: 188), é considerado 'raro' en portugués e incluído entre os diminutivos con matiz afectivo, aplicado fundamentalmente a adxectivos, como delgadocho, grandocho, pequenocho (véxase Freixeiro Mato 1996: 55). Hai un posible antecedente medieval, Pedrocho, en 1279 (véxase cap. 3). Nos hipocorísticos aparece en 13 formas (un 7\%), repartidas case equitativamente entre masculinos e femininos: Pilocha, Nocha, Marinocha, Quinocha/o Tocho, Locho, Cardocho e Vitocho.

5.2.2.7. - ol-alo (lt. -ŏLUS, por vía erudita, que pasou de átono a tónico), ten na lingua común un leve valor depreciativo, con fortes connotacións de rexistro familiar e coloquial: merendola, paiolo, pedrolo, rapazolo, barrigola..., e lexicalizacións, como cabezolo, cachola, ferreirolo (véxase Ferreiro 1997: 187). É sufixo case exclusivamente aplicado a nomes masculinos (Cholo < Xosé Luís, Fincholo, Vitolo, 
Tiñolo < Martiño, Carolo < Carlos, Xanzolo), pois só o rexistramos nun feminino (Quinola). Non incluímos aquí o moi abundante Manolo/Manola, pois neles hai monotongación e remate cun morfema xenérico, $-o$ ou - $a$, aínda que si debeu influír a analoxía cos portadores deste sufixo.

Unha variante deste sufixo debe ser a terminación -olas, para o masculino, que aparece en Andolas (< Antonio), Cholas (< Vicente) e Xanzolas $(<$ Xan, co mesmo interfixo do diminutivo Xanciño). Este $-s$ final vese tamén nalgúns dos hipocorísticos da Idade Media: Maricas, Myngachos (véxase supra, cap. 3).

5.2.2.8. -ocas. Posiblemente sexa a mesma variante en -as co devandito sufixo -olas, que tamén está en -icas (choromicas, mexericas, acusicas, merdicas), a partir do sufixo -oco (bichoco, paifoco, pailaroco, vinchoca) de claro valor despectivo en orixe (véxase Ferreiro 1997: 196). No corpus empregado só está no masc. Xanocas; en Xocas só é segmentable -as, pois o -k- pertence á raíz (Xoaquín).

5.2.2.9. -ot-a/e. Probablemente de orixe francesa, tiña un valor orixinariamente diminutivo e despois aumentativo, quizais pola vogal posterior media aberta (Alonso Núñez 2000: 151). Ten antecedentes medievais que parecen apoiar a orixe francesa (Perrot, no séc. X; tamén Pedrote en 1424: véxase supra) Aínda que é bastante produtivo na lingua común cun matiz aumentativo e despectivo (cf. gordote, pingota, pipote, rapazote, vellote...), como hipocorístico só o rexistro en Pepote e en Mingote (no XVIII-XIX tamén había Mingota), procedentes de nomes de tal frecuencia que teñen unha chea de derivacións, mesmo algunha, coma esta, que non é común noutros hipocorísticos.

5.2.2.10. ech-o (<lt. -esco + ŪLU). No corpus hai oito hipocorísticos, e, excepto Checha $(<$ Xosefa), todos eles masculinos: Tonecho, Manecho/Maecho $(<$ Manuel), Cochecho (<Xosé Manuel), Gorecho (< Goro < Gregorio), Necho (< Andrés), Josecho. Na lingua común foi relativamente rendible sobre bases substantivas e adxectivas: cornecho, rabecho, gordecho (véxase Freixeiro Mato 1996: 55).

5.2.2.11. -ec-o. Presente en escasos substantivos con matiz despectivo como libreco, soneca, burreco, na lingua común é improdutivo con trazo [+ humano] (Alonso Núñez 2000: 151), e, nembargantes, no corpus hai dous hipocorísticos masculinos: Neco (< Valentín) e Toneco, un dos poucos comúns cos sufixos hipocorísticos do portugués (véxase Leite de Vasconcelos 1927: 457).

5.2.2.12. $-e l-a$ (< lat. $\breve{L L L U S)}$. Este sufixo xa no séc. XIII deixara de ser rendible como diminutivo, pola compentencia de -iño (Alonso Núñez 2000:146-7). De feito, as palabras que o levan están lexicalizadas, e se ben nalgúnhas aínda se per- 
cibe o matiz diminutivo, por comparalas coa base (campelo, portela, ruela, soutelo...), noutras non (cachelo, codelo, mantelo, rodela), e todas elas admiten perfectamente o diminutivo en -iño. Unicamente pode considerarse produtivas as formas nominais de base verbal en -dela (apalpadela, comedela, mordedela: véxase Freixeiro Mato 1996: 50-1). Posiblemente a súa vitalidade na antroponimia vén da popularidade de Carmela, onde, se ben hoxe se sente como diminutivo de Carme, na realidade está na orixe etimolóxica: o topónimo Carmelus en lat., Kármelos en grego, e estes do hebreo Karmel 'xardín' (DNG s.v.); o nome estandarizouse en Carme (port. Carmo, cast. Carmen), e Carmela foi considerado variante hipocorística; na antroponimia, amais desta, aparece Lucha e Mela (as dúas formas apocopadas de Carmela), Maruxela e Terela (nestes dous últimos casos probablemente por analoxía con Carmela). En Lela, Nela e Nelo non hai sufixo, pois é aférese de Manuela e Manuel, respectivamente, con monotongación e, no primeiro caso, reduplicación da consoante da última sílaba; en Nelo, ademais, engádese un morfema para indicar o xénero, igual ca en Sabela $(<$ Isabel).

5.2.2.13. -iñ-a/o < lat. -īNUs: é o sufixo máis vizoso e produtivo de todos cantos expresan a diminución e a afectividade (véxase un amplo tratado sobre el en Freixeiro Mato 1996: 63-117), de maneira que calquera das formacións anteditas é susceptible de admitilo. Tamén se atesta con frecuencia nas formas medievais (Afonsino, Fernandijño, Gonçaluino, Johanino, Meendiño, Aldariña, Mayoriña, véxase supra, cap. 3). Aquí procurei incluír só os que alcanzaron substantitividade, isto é, os que funcionan plena e exclusivamente como designadores da persoa; acadan en conxunto un $8 \%$. En tal caso están algúns nomes femininos tan frecuentes que admiten practicamente tódalas posibilidades de sufixación para evitar homonimias: Carmiña, Mariquiña e Pepitiña, estes dous últimos con acumulación de sufixos. Nos masculinos, aparece o propio sufixo, Iño, como hipocorístico de dous nomes distintos (Luís e Darío), Siño $(<$ Celso), e dous derivados en última instancia de Xosé: Cheíño e Piño (este a través de Pepe). Debemos consignar aquí a solución dialectal alternativa a -iño, -ín, como en Pepín, que se documenta dialectalmente en falas do leste de Lugo e no galego de Asturias e do Bierzo.

5.2.2.14. -it-a/o (<-ITTUS, de orixe controvertida: véxase Alonso Núñez 2000: 166). É o sufixo diminutivo por excelencia do español (e, despois de -iño, tamén do portugués). En galego existe lexicalizado en cabrito, e tamén se rexistra como diminutivo con certa rendibilidade nalgunhas áreas (concretamente, en Castrelo do Val: véxase Alonso Núñez 2000: 166). Documéntase só con valor antroponímico con certa frecuencia en Galicia (no noso corpus, cun 11,5\%: en Pepito, Pepita e Pepitiña, amais de Sito e Josito < Xosé, Nito < Laureano, Tito, que vale para moi diversos nomes, como Antón, Lourenzo, Ricardo..., ou Marita para os que comezan por María etc.), vitalidade que pode explicarse pola interferencia do castelán, sobre todo tendo en 
conta que se rexistran sobre todo no séc. XX. Porén, quizais non sexa casual que unha das hipóteses máis defendibles sobre a súa orixe, a de Diez, que postula unha orixe xermánica, o faga principiar polos nomes propios (apud Alonso Núñez 2000: 166), pois en galego o común é rexistralo soamente en nomes propios, non na súa función diminutiva nos nomes comúns, onde -iño non ten competencia ${ }^{14}$.

5.2.2.15. - ic-a/o (<-ICCUS). Con certa produtividade nalgunhas áreas dialectais, documéntase ademais na toponimia da área oriental da provincia de Ourense e zonas limítrofes; en portugués e en castelán tamén se considera dialectal. A súa orixe podería estar nalgúns nomes propios non latinos, especialmente de mulleres (Alonso Núñez 2000: 164). Como antropónimo rexistrámolo en Toñico e Perico, formas en regresión ${ }^{15}$, e mais no feminino Marica, xa case desusado (aínda que documentado desde a Idade Media, como vimos arriba): empregado por Rosalía xunto co seu derivado Mariquiña (Freixeiro Mato 1996: 126), rexístrase no Cancioneiro popular, e no TILGa aparece como nome propio só na década de 1930; a especialización semántica que adquiriu a palabra, utilizada como voz despectiva para 'homosexual', é un poderoso impedimento para continuar servindo como diminutivo afectuoso.

5.2.2.16. - ach-o (lat. -ACŬLU en combinación con -asco ou deformación do aumentativo -azo (véxase Ferreiro 1997: 193), presente na lingua desde a época medieval, ten valor fundamentalmente pexorativo (como en ricacho, covacha), pero tamén diminutivo (regacho, anguiacho). Non é considerado como diminutivo produtivo no galego actual, senón cun valor despectivo (Alonso Núñez 2000: 156). A forma Mingacho, unha das escasas con antecedentes documentados na Idade Media (en 1422, véxase supra, cap. 3), procede do cancioneiro de Pérez Ballesteros, datado en 1885 (véxase Sánchez Rei 2006). En Pacho (< Plácido) pode recoñecerse este sufixo, aínda que tamén se pode interpretar como un caso de truncamento, semellante ao de Concha $(<$ Concepción).

\subsubsection{Uso de consoantes palatais: / $/ \mathrm{t} / \mathrm{l} / \mathrm{J} / \mathrm{/} / \mathrm{n} /$}

5.2.3.1. Xa vimos nos sufixos antroponímicos que os máis abundantes son os que teñen $c h$, por mor da escaseza desta consoante na lingua común. Fóra da súa presenza neles, este son aparece no 15,5\% dos hipocorísticos, tanto en posición inicial

\footnotetext{
${ }^{14}$ Algo semellante pasa en catalán: rexístrase o castelanismo -ito como sufixo hipocorístico (Pedrito, Juanito, Pepito etc.: García i Osuna 2003: 332), e no castelán de Zaragoza, onde o sufixo habitual na lingua común é -ico, para o que "debió influir el prestigio de la lengua nacional” (Buesa 1988: 1620).

${ }^{15}$ Só as atestamos no Cancioneiro popular; Perico, ademais, úsano o Padre Isla nas súas cartas (escritas en castelán) e Cunqueiro na Escola de menciñeiros (dato que agradezo a $\mathrm{M}^{\mathrm{a}}$ Xesús Nogueira).
} 
(como palatalización de sibilante + i,e,a: Che/Cheíno/Chelís/Cheto $<$ Xosé, Chenchalo $<$ Inocencialo, Chicho $<$ Francisco, Chinto $<$ Xacinto, Chefa $<$ Xosefa, Chente $<$ Vicente, Chalo $<$ Gonzalo, Chano $<$ Luciano, Chon/Chona $<$ Asunción, Chelo < Consuelo, Rosalía > Chelía, ou doutras consoantes: Chelipe < Felipe, Chara/Charo < Rosario, t $j$ : Santiago > Chago), como medial (Machuca, Merche, Pancho), ou engadida á última sílaba do nome orixinario: Fincholo, Moncho (para este último, como para Menchu, tense proposto unha orixe vasca). Tamén pode aparecer repetida nas dúas sílabas, o que aumenta o seu carácter expresivo: Chencha/o, Chichalo, Chincha, Choncha, Chucho, Chuchú, Chuchi. E, finalmente, nalgúns a motivación fonética apenas se albisca, tal é a distancia que hai entre nome orixinal e hipocorístico: Cholo < Andrés/Eliseu/Henrique/Gonzalo, Cholas $<$ Vicente, Chiruca $<$ Mercedes.

5.2.3.2. A mesma intencionalidade expresiva ten a palatalización en $/ / /$, moito menos frecuente (un 1,5\%), seguramente por ser un son moito máis habitual na lingua común: de aí temos Xenxalo < Inocencialo, Xonxa $<$ Asunción, Xabela $<$ Isabel, Xuxo < Suso, e, sen motivación fonética aparente, Xoxardo $<$ Leonardo.

5.2.3.3. En canto á nasal palatal, só aparece no sufixo -iño e en Toño, como palatalización normal do grupo $n j$. E, por último, tamén cabería mencionar a palatalización en /J/ procedente do grupo rj que se dá na forma castelá Toya.

\subsubsection{Outros procedementos}

5.2.4.1. A monotongación (11\%) aparece cando no nome orixinal hai un ditongo crecente: ia > a (Mila, Tila < Otilia, Tona, Totora), io $>$ o (Goro, Telo < Eleuterio, Tono), ue > e/o (Chelo, Nelalo; Manolalo), oa > ua> a/o (Xan, Xaquín, Xaquina; Xocas, Xoquín). Ao seren ditongos de pouco rendemento na lingua, a linguaxe infantil tende a simplificalos.

5.2.4.2. En casos en que o nome orixinal carece dun morfema xenérico, engádeselle no hipocorístico (11\%): é o que ocorre cos abundantes marianos en -ción (Chicha $<$ Concepción, Chincha $<$ Encarnación, Chona $<$ Asunción, Concha $<$ Concepción, PuralPorfica $<$ Purificación), ou con outros femininos non rematados en - $a$, como Tilda < Matilde, Trina < Trinidad, Sabela < Isabel, Chara < Rosario, Pilara < Pilar, Lola < Dolores; ou masculinos non rematados en -o: Manolo/Lolo/Nelo < Manuel, Seso/Pucho < Xosé, Felo < Rafael, Rico/Queco < Henrique, Suso/Chucho < Xesús, ou Quino < Xoaquín. Pero se lle engadimos aquí os casos en que o morfema xenérico é engadido co sufixo a nomes que non presentan orixinariamente remate en $-o$ ou $-a$ (Lucha $<$ Carme etc.), a porcentaxe elé- 
vase ao $65 \%$, co cal dá a impresión de que á hora de formar os hipocorísticos se ten ben presente a distinción xenérica ${ }^{16}$.

5.2.4.3. As reduplicacións, típico recurso da linguaxe infantil, constitúen un procedemento non demasiado rendible $(6,5 \%)$, ao contrario do que ocorre en portugués: de feito, Leite de Vasconcelos (1926: 485-489) dedícalle, pola súa importancia, un capítulo enteiro. Ademais, á vista dos casos en que aparece, semella bastante recente, pois a maior parte dos referidos son formas modernas, non tradicionais: reduplicación da sílaba tónica (LolólLola $<$ Dolores, Totó $<$ Antonio, Totora < Vitoria, Seso < Xosé, Sesa < Xosefa), da primeira sílaba (Teté < Tereixa), baseándose na consoante da última sílaba (Fefa $<$ Xosefa, Lela $<$ Manuela, Quique, Quico, Queco), ou con ch (Cheché, Chuchú). O caso do abundantísimo Pepe (que deu lugar a moitos derivados e mais á forma feminina) é máis problemático, pois a súa orixe é discutida: podería vir do - $p$ final dunha forma catalá Josep ou italiana Gioseppe, con redobro, ou, máis probablemente, "da duplicación do tema tónico -ep, forma antiga por perda da aspiración en Joseph" (DNG s.v. Xosé $)^{17}$.

5.2.4.4. Algunhas deformacións veñen dadas claramente por simplificacións de grupos consonánticos, normalmente con $r$, derivadas das dificultades dos nenos para aprender a articulalos: Menani $<M^{a}$ Carme, Lalo $<$ Bernardo/Hilario. Rexístrase algunha metátese, como en Pacucho > Pachuco, Chuco.

5.2.4.5. Por último, hai algúns hipocorísticos que desde o punto de vista fonético non teñen nada que ver (ou apenas) co nome do que proceden. Poden ser motivados para outros nomes, pero aquí parecen totalmente arbitrarios. Nestes casos o seu uso está máis próximo aos alcumes (e, por tanto, a súa motivación pode ser calquera) cá das formacións hipocorísticas habituais: así Chelo de Natividad, Cholo de Gonzalo, Henrique e Eliseu; Suso de Evaristo, Pilucha de Angustias, Pitusa de Xosefa, Nenuca de Concepción, Chiqui ou Queca de Helena. Outras veces, aínda sen ver clara esa motivación, son hipocorísticos convencionalmente aplicados a certos nomes, como Chiruca $<$ Mercedes.

\footnotetext{
${ }^{16}$ Aínda que non deixa de haber casos de hipocorísticos válidos para os dous sexos, como Loló (de Manuel ou de Dolores) e, por outro lado, como xa se dixo, tamén hai sufixos rematados en -as para o masculino (como -ocas e -olas).

${ }^{17}$ Esta hipótese parece ser apoiada pola existencia dos antigos hipocorísticos Chisepe e Xepe. Ademais, Gonzalo Correas dicía en 1626 que "los del vulgo la quitan [la f], y dicen José; pocos en nombres de persona dicen Josef, porque es contra el uso Castellano, i por eso le mudamos en Iusepe, Iusepa" (apud Buesa 1988: 1622).
} 


\section{As novas tendencias na formación de hipocorísticos}

As descritas ata aquí eran as tendencias tradicionais de formación de alcumes, que polos testemuños escritos, podemos dicir que eran válidos durante todo o século XIX e o XX. No entanto, as enormes mudanzas da nosa sociedade no último terzo do XX tiveron o seu reflexo antroponímico nunha variación dos nomes propios: nos últimos anos do século asistimos a unha renovación do corpus antroponímico maior cá producida paulatinamente nos últimos catrocentos anos (véxase Boullón 2007: 99, 111). Iso ten as súas consecuencias evidentes para o tema que nos ocupa, pois, coa mudanza de tendencias onomásticas, tamén mudou o sistema de formación de hipocorísticos, xa que o habitual é os hipocorísticos formárense a partir dos nomes máis frecuentes. Agora, eses Manuel, Xesús, Antón, Carme, Xosefa ven diminuír a súa preferencia de tal maneira que os hipocorísticos, se os hai, créanse en boa medida a partir doutros nomes ${ }^{18}$. Ao comparar o ránking dos nomes máis frecuentes nos tres períodos considerados, verase isto dunha forma moi gráfica: nos nomes femininos, na última década do XX só un se repite ${ }^{19}$; téñase en conta que hai moita máis distancia cronolóxica entre o séc. XVIII e o XX que entre este e a súa última década. Nos nomes masculinos, dado o seu tradicional maior conservadorismo con respecto aos femininos, isto non se aprecia de forma tan radical.

Os 20 nomes máis frecuentes en diversos períodos

(en letra grosa, indícanse os que se repiten con respecto ao período anterior)

\section{Femininos}

\begin{tabular}{|c|c|c|}
\hline Séc. XVIII & Séc. XX & 1990 \\
\hline Maria & MARIA CARMEN & LAURA \\
\hline Antonia & MARIA & ANDREA \\
\hline Josepha & CARMEN & MARIA \\
\hline Francisca & JOSEFA & SARA \\
\hline Juana & DOLORES & ALBA \\
\hline Rosa & MARIA DOLORES & CRISTINA \\
\hline Dominga & MARIA PILAR & LUCIA \\
\hline Ysavel/Ysabel & MARIA JOSE & MARTA \\
\hline Ana & MARIA TERESA & PAULA \\
\hline
\end{tabular}

18 Os hipocorísticos tidos en conta para este período cronolóxico están tirados de Hafner 2004 (a partir de L), baseados en 802 cuestionarios feitos a rapaces nacidos entre 1973 e 1982, en 15 puntos de toda a xeografía galega, do coñecemento directo e mais de traballos de doutoramento realizados por Laura Sar Pose (curso 2003-2004), sobre rapaces de $3^{\circ}$ e $4^{\circ}$ da ESO do Concello de Muxía e Lara Rozados Lorenzo (curso 2004-2005), sobre os nomes dos socios da Asociación cultural e xuvenil Itaca, de Santiago de Compostela.

19 Véxase unha análise somera da evolución dos nomes en Galicia no séc. XX en Boullón 2002. Os datos do séc. XX, como xa se dixo, están tirados do censo do INE de 2001, que carece de acentos. 


\begin{tabular}{|l|l|l|}
\hline Séc. $\mathbf{X V I I I}$ & \multicolumn{1}{|c|}{ Séc. $\mathbf{X X}$} & \multicolumn{1}{c|}{$\mathbf{1 9 9 0}$} \\
\hline Manuela & MANUELA & ANA \\
\hline Angela & ANA MARIA & NOELIA \\
Cathalina & MARIA LUISA & RAQUEL \\
Pasqua & MERCEDES & SANDRA \\
Andrea & MARIA ISABEL & PATRICIA \\
Benita & ROSA & NEREA \\
Magdalena & CONCEPCION & TANIA \\
Theresa & PILAR & LORENA \\
Mariana & MARIA JESUS & TAMARA \\
Ygnacia & ISABEL & BEATRIZ \\
Caietana & MARIA ANGELES & IRIA \\
\hline
\end{tabular}

2. Masculinos

\begin{tabular}{|l|l|l|}
\hline \multicolumn{1}{|c|}{ Séc. XVIII } & \multicolumn{1}{c|}{ Séc. XX } & \multicolumn{1}{c|}{ 1990 } \\
\hline Juan & MANUEL & ADRIAN \\
Francisco & JOSE & DAVID \\
Joseph & ANTONIO & DANIEL \\
Domingo & JOSE MANUEL & ALEJANDRO \\
Pedro & JESUS & PABLO \\
Manuel & JOSE LUIS & DIEGO \\
Andres & JOSE ANTONIO & IVAN \\
Benito & FRANCISCO & JAVIER \\
Gregorio & CARLOS & RUBEN \\
Ygnacio & RAMON & SERGIO \\
Antonio & LUIS & MANUEL \\
Bernardo & DAVID & MIGUEL \\
Miguel & JAVIER & CARLOS \\
Alonso & FERNANDO & JORGE \\
Thomas/Thome & PABLO & ALBERTO \\
Nicolas & JUAN & CRISTIAN/CHRISTIAN \\
Julian & ANGEL & MARTIN \\
Vicente/Vizente & DANIEL & BRAIS \\
Jacobo & ALBERTO & MARCOS \\
Bartolome & JOSE MARIA & OSCAR \\
\hline
\end{tabular}


Pero non se trata só da mudanza dos nomes, senón tamén da mudanza dos procedementos da formación de hipocorísticos. A partir de agora, o sistema por excelencia xa non será a aférese e a utilización dos sufixos tradicionais $-u c h o /-a,-u c o /-a$ -ocho/- $a$, senón a apócope e o remate en - $i$ átono, ao modo dos hipocorísticos ingleses.

Isto non significa que haxa unha creba repentina e total cos procedementos anteriores, senón un cambio na preferencia deles. No que respecta aos sufixos, séguense utilizando, pero agora o preferido parece ser -iñ-al-o (Variño, de Álvaro, Beliña, de Belén, Noeliña, Lauriña, Vanesiña, Yoliña, Natiña $(<\text { Natividad })^{20}$, rexistrado con maior frecuencia ca -ech-al-o (Larecha), -uc-a (Nesuco) ou -uch-al-o (Gelucha, Bucha < Beatriz, Javucho, Mucho < Xaime) e ca o outro de diminución, -it-al-a (Jorgito, Pablito). Nalgún caso o sufixo tradicional defórmase á maneira inglesa, como este -uca que pasa a ser -uqui, con $i$ átono: Luqui $<$ Candeluqui $<$ Candela, ou -ucha $>-u c h i$, en Piluchi. Ou aparecen sufixos máis exóticos, como en Ana > Anuska, Carme > Carmuna.

Tamén segue habendo palatalizacións coa africada prepalatal xorda, $c h$, por exemplo, en Luchi < Lucía, Chechu/Chucho < Jesús, Chesco < Francisco ou coa fricativa prepalatal xorda, $x$ (Xío, de Rocío). E outros procedementos propios da linguaxe infantil, como a substitucións de determinados sons polas oclusivas xordas, máis fáciles de pronunciar, como en Jorge > Coque, Diego $>$ Queco, formacións con reduplicación parecidas ás xa vistas en Henrique $>$ Quique, Francisco $>$ Quico.

En canto aos procesos de recorte de sílabas, rexístranse así mesmo aféreses (como a tradicional Gregorio $>$ Goro), que poden ser dunha sílaba (Benedicta $>$ Dita, Elena $>$ Lena/Leni, Gelucha $>$ Gelu, Vanesa $>$ Nessa, Yolanda $>$ Landa, Alvaro $>$ Varo, Armando > Mando), mantendo só a última (Agustín > Tin, Martín > Tin), ou rematar en $-i$ átono (Raquel $>$ Queli/Kely/Quely, Alejandro $>$ Jandri). E algún caso de síncope, afectando todas as consoantes: Úrsula $>U ́$ U.

Pero agora os máis abundantes son os distintos tipos de acurtamento por apócope, que reducen o nome ás dúas primeiras sílabas ou mesmo á primeira, de maneira que se van producindo sucesivos cortes do nome orixinal:

Déborah: Debo, Deb, De.

Lorena: Loren, Lore/Loro, Lo.

No caso de os nomes non levaren o acento na primeira sílaba dáse asemade un desprazamento acentual (Xosé > Xose, Xos, Xo), nun procedemento que pode come-

\footnotetext{
${ }^{20}$ En Osquiñar e Marquiños a secuencia iño é un infixo, pois se introduce no interior da palabra.
} 
zar simplemente coa última consoante, como en Óscar > Osca, Miguel > Migue, pero que habitualmente suprime a última sílaba:

Andrea: Andre, Begoña: Bego, Inés: Ine, Nerea: Nere, Noelia: Noe, Vanesa: Vane, Lorena: Lore, Isabel: Isa, Sabela: Sabe, Beatriz: Bea, Soraya: Sora, Susana: Susan, Vanesa: Vane, Verónica: Vero.

Adrao: Adra, Agustín: Agus, Antonio: Anto, Bernaldo: Bérnal, Eduardo: Edu, Ernesto: Ernes, Manuel: Manu, Norberto: Nórber.

Obsérvese que moitos destes nomes coinciden en ter a segunda sílaba rematada en $-i$ :

Alicia: Ali, Fátima: Faty, Fabiola: Fabi, Leticia: Leti, Lydia: Lydi, Iria: Iri, Lucía: Luci / Luchi, Mónica: Moni, Noelia / Nélida: Neli, Sofía: Sofi; Sonia: Soni/Soñi, Silvia: Silvi.

Damián: Dami, Daniel: Dani, Ramiro: Rami, Rodrigo: Rodri.

Seguramente esta razón, xunto coa existencia de hipocorísticos previos como Pili ou Loli facilitou que moitos nomes pasasen a rematar en $i$ átono, contrario á estrutura fonética do galego (que en posición final átona só ten tres vocais, $a, e, o$ ) ${ }^{21}$. Así, moitos nomes que non tiñan - $i$ na súa composición acaban rematando nesta vogal, para facelos cadrar (ou semellarse) ás correspondentes formas inglesas:

Carme: Camy, Cristina: Crisi, Dolores: Doly, María: Mery, Mercedes: Merchi, Olalla: Oli, Patricia: Patri/Pati/Patty, Raquel: Raqui/Raquy/Racky/ Rachy, Rosalía: Rosy, Rosario: Rosi, Sabrina: Sabri, Sandra: Sandy, Soraya: Sori, Susana: Susi/Susy, Tamara: Tami, Vanesa: Vani, Verónica: Veri, Yolanda: Yoli.

Adrián: Adri, Bernaldo: Berni, Iván: Ivi, Maximino: Maxi, Ricardo: Riki/Ricky, Rubén: Rubi/Rugui/Ruchi.

Un paso máis no acurtamento levou ao incremento das formas monosilábicas (outra das diferenzas con respecto aos tradicionais, onde os monosílabos eran minoritarios), que mesmo rematan en consoantes insólitas en posición final (tal como Mich, Mont ou Deb).

Cristina: Cris, Julia: Ju, Lucía: Lu: Montserrat: Mont, Nerea: Ne; Raquel: Ra, Rosario/Rocío: Ro, Silvia: Sil, Sonia: Son.

\footnotetext{
${ }^{21}$ Así, non era raro oílos pronunciados como Pile ou Lole, que se axusta máis á composición das palabras patrimoniais.
} 
Alfonso: Al, Andrés: Nes, Francisco: Fran; Jonathan: Jon, Miguel: Mich, Pablo: Pa.

E, coincidindo ou non con estes procedementos, é usual tamén a adopción da forma foránea correspondente ao nome orixinario, normalmente inglesa (Beatriz: Betty; Ricardo: Richard/Richi), pero non unicamente, porque tamén se atopa unha adaptación fonética do italiano (Luilli < Luis), ou unha forma francesa pero con pronuncia grave (Míchel < Miguel, nome espallado por un futbolista).

En definitiva, os cambios habidos no corpus dos nomes de Galicia nos últimos anos reflectíronse na formación dos hipocorísticos non só na mudanza dos nomes dos que parten, senón tamén na maneira de facelos, que acusan en gran medida a influencia dos nomes ingleses a través da cultura norteamericana.

\section{Conclusións}

Os hipocorísticos constitúen un sistema alternativo ao prenome oficial, formado por alteracións fonéticas deste, que se utiliza en ámbitos de familiaridade e informalidade e con frecuencia son empregados só ata o estado adulto da persoa. Por esas razóns non se adoitan consignar de maneira sistemática e a súa recollida é máis laboriosa, pois a súa aparición por escrito se restrinxe a recollidas de campo, obras literarias ou específicas de antroponimia e necrolóxicas dos xornais.

Na formación dos hipocorísticos adóitanse combinar varios tipos de procedementos fonéticos e morfolóxicos. Os tradicionais, que se comezaron a configurar na Idade Media e continuaron en boa medida ata agora, eran, en primeiro lugar, a supresión de sons, principalmente a aférese (normalmente da sílaba inicial); en segundo lugar, o engadido de sufixos que na lingua común adoitan ter un valor diminutivo-afectivo, ou máis habitualmente despectivo, pero na antroponimia é sobre todo afectivo; o máis repetido era -uch-. En terceiro lugar, a presenza de consoantes palatais, especialmente /t//, seguramente por ser a menos frecuente das consoantes galegas, polo que ten un alto valor expresivo. E, por último, hai outros recursos menos recorridos, como as reduplicacións, a monotongación ou o engadido dun morfema xenérico cando o nome orixinal non o ten. Tamén hai hipocorísticos sen motivación fonética aparente, que pola súa arbitrariedade na asignación se semellan máis aos alcumes.

Este sistema de formación foi mudando na segunda metade do século XX: aumentaron as reduplicacións e, co cambio lexislativo que permitiu a incorporación de novos nomes (pois agora xa non son exclusivamente españois), mudou tamén o xeito de acurtalos: sen abandonar de todos os antigos procedementos, prefírense as formas apocopadas, proliferan as monosilábicas, impórtanse hipocorísticos e pro- 
cedementos diminutivos ingleses. A influencia da cultura de masas incide na uniformización con respecto a outros ámbitos lingüísticos e á perda dos sinais de identidade característicos ata o momento.

\section{Bibliografía}

Alonso Núñez, A. (2000): "Os sufixos nominais diminutivos do galego actual”, Verba, 27: 133-174.

Boyd-Bowman, P. (1955): "Como obra la fonética infantil en la formación de hipocorísticos”, Nueva Revista de Filología Hispánica, 9: 337-366.

Boullón Agrelo, A. I. (1999): Antroponimia medieval galega (séculos VIII-XII) (Tübingen: Niemeyer).

Boullón Agrelo, A. I. (2002): "2.3. Galizia”, en "I prenomi più frequenti nel mondo alla fine del secondo millennio", Rivista Italiana d'Onomastica, 8: 640-642.

Boullón Agrelo, A. I. (2007): "A escolla dos nomes en Galicia a finais do s. XX", en Luz Méndez / Gonzalo Navaza (eds.): I Congreso Internacional de Onomástica Galega Frei Martín Sarmiento. Santiago de Compostela, 2-4 de setembro de 2002: 99-114 (Santiago de Compostela: Asociación Galega de Onomástica / Real Academia Galega).

Buesa Oliver, T. (1988): "Recursos fónicos en la afectividad de los antropónimos", en Ariza, M. / Salvador, A. / Viudas, A. (eds.): Actas del I Congreso Internacional de Historia de la Lengua Española (Cáceres, 30 marzo-4 abril 1987). Vol. II: 1613-1640 (Madrid: Arco).

Diéguez Gonçález, J. (2000): O patronímico na onomástica pessoal dos documentos notariais galegos e portugueses da Baixa Idade Média (1250-1500). Tese de doutoramento (inédita). Universidade de Santiago de Compostela. 2 vols. Publicación en CD-Rom, 2002.

Fernández Salgado, X. A. (no prelo): “A propósito da antroponimia en Majina, ou a filla espúrea", en II Congreso Internacional de Onomástica Galega. Pontevedra, 19, 20 e 21 de outubro de 2006 (Asociación Galega de Onomástica / Instituto da Lingua Galega / Universidade de Vigo).

Ferreiro, M. (1997): Gramática histórica galega. Vol. II. Lexicoloxía (Santiago de Compostela: Laiovento).

Freixeiro Mato, X. R. (1996): Os diminutivos en galego (Vigo: A Nosa Terra).

García i Osuna, A. (2003): "La sufixació en els malnoms", en Casanova, E. / Valero, Ll. R. (eds.): XXIX Col.loqui de la Societat d'Onomàstica. Teulada, desembre 2002: 325-365 (València: Denes).

Pensado Tomé, J. L. (1991): "Historia de 'Farruco"”, en Galicia en su lengua y sus gentes (ensayos): 137-139 (A Coruña: La Voz de Galicia). 
Piel, J. M. (1949): “Os nomes dos santos tradicionais hispânicos na toponímia peninsular”, Biblos: 25: 287-353.

Regueira, X. L. (1989): A fala do Norte da Terra Cha. Tese de doutoramento (inédita). Universidade de Santiago de Compostela.

Regueira, X. L. (2007): "Patróns fónicos dos nomes de persoa", en Méndez, L. I Navaza, G. (eds.): I Congreso Internacional de Onomástica Galega Frei Martín Sarmiento. Santiago de Compostela, 2-4 de setembro de 2002: 239-256 (Santiago de Compostela: Asociación Galega de Onomástica / Real Academia Galega / Instituto da Lingua Galega).

Vasconcelos, J. Leite de (1928): Antroponimia Portuguesa (Lisboa: Imprensa Nacional).

Weinhold, N. (2007): "La morphologie dérivationelle historique dans le dictionnaire PatRom", en Dictionnaire historique de l'anthroponymie romane Patronymica Romanica (PatRom), vol. I.1 Introductions. Cahier des normes rédactionnelles. Morphologie. Bibliographies: 111-129. Publié pour le collectif PatRom par Ana María Cano González, Jean Germain et Dieter Kremer (Tübingen: Max Niemeyer).

\section{Fontes para os hipocorísticos medievais}

CDFerreira = Fernández de Viana y Vieites, J. I. (1994): Colección diplomática del monasterio de santa María de Ferreira de Pantón (Lugo: Deputación Provincial)

CDMaia = Maia, C. de Azevedo (1986): História do galego-portugués. Estado lingüístico da Galiza e do Noroeste de Portugal do século XII ao século XVI (com referência á situação do galego moderno) (Coimbra: INIC).

CDRamirás = Lucas Álvarez, M. / Lucas Domínguez, P. P. (1988): San Pedro de Ramirás. Un monasterio femenino en la Edad Media. Colección diplomática (Santiago de Compostela: Public. de Caixa Galicia).

CDRibadavia = Enríquez Paradela, M. C. (1987): Colección diplomática del monasterio y convento de Santo Domingo de Ribadavia. Anexo 8 do Boletín Auriense (Ourense: Museo Arqueolóxico Provincial).

CM = Cal Pardo, E. (1990): Catálogo de los documentos medievales escritos en pergamino, del archivo de la Catedral de Mondoñedo (871-1492) (Lugo: Deputación Provincial).

CDMondoñedo = Cal Pardo, E. (2005) [1999]: Colección diplomática medieval do Arquivo da Catedral de Mondoñedo: transcrición íntegra dos documentos (Santiago de Compostela: Consello da Cultura Galega).

DocDevOurense $=$ Ferro Couselo, X. (1996) [edición facsímil da ed. de 1967]: A vida e a fala dos devanceiros. Escolma de documentos en galego dos séculos XIII ao $X V I .2$ vols (Vigo: Galaxia). 
DocNoia = Barreiro García, M. C. (1995): A documentación notarial do concello de Noia (ss. XIV-XVI). Lectura, edición e léxico. Tese de doutoramento (inédita). Universidade de Santiago de Compostela.

DocUnivSantiago = Lucas Álvarez, M. / Justo Martín, Mª X. (1991): Fontes documentais da Universidade de Santiago de Compostela. Pergameos da serie Bens do Arquivo Histórico Universitario (Anos 1237/1537). Edición diplomática (Santiago de Compostela: Consello da Cultura Galega).

LNotasRianxo = Tato Plaza, F. R. (1999): Libro de notas de Álvaro Pérez, notario da terra de Rianxo e Postmarcos (1457). Edición e glosario (Santiago de Compostela: Consello da Cultura Galega).

PadrónsOurense = López Carreira, A. (1995): Padróns de Ourense do século XV. Fontes estatísticas para a historia medieval de Galicia (Santiago de Compostela: Consello da Cultura Galega).

TBieitoSantiago = Fernández Salgado, A. (1999): Documentación medieval de San Bieito do Campo. Memoria de licenciatura (inédita). Universidade de Santiago de Compostela.

TCelanova = Sáez, C. / Sáez, E. (1996/2000/2006): Colección diplomática del monasterio de Celanova (842-1230). I: 842-942. II: 943-988. III: 989-1006 (Madrid: Universidad de Alcalá).

TSobrado = Loscertales de García Valdeavellano, M. P. (1976): Tumbos del monasterio de Sobrado de los Monjes. 2 vols. (Madrid: Dirección General del Patrimonio Artístico y Cultural, Archivo Histórico Nacional).

\section{Fontes onomásticas dos séc. XVII ao XIX}

Álvarez Blanco, R. / Rodríguez Montederramo, X. L. (2004): “Escrita epistolar en galego: a correspondencia de Don Diego Sarmiento de Acuña, I Conde de Gondomar (1567-1626)" (I), Boletín da Real Academia Galega, 365: 253-291.

"Carta recomendada" (1812), en Gaceta Marcial y Política de Santiago. Reproducida en Prosa galega: 21-22.

Diálogo en na Alameda de Santiago entre Cristovo, Farruco, Bartolo e Freitoso (1836) (Santiago de Compostela: Imprenta de J. Núñez Castaño). Reproducido en Prosa galega: 45-50.

Dobarro Paz, X. M (2000): "Vicente Turnes e a poesía áulica", en Rodríguez, J. E. (ed.): Estudos dedicados a Ricardo Carvalho Calero. Vol. 2: 205-212 (Santiago de Compostela: Parlamento de Galicia / Universidade de Santiago de Compostela).

Encuentro y coloquio que tuveron na ponte da Chainsa cercana a vila de Noya, Gurumete, R. Pedro de Atanasio, è Pepe Alonso, ò dia 13 de Noviembre de 1836, en que se nombrou na-quela vila ò Auntamiento Costitusional (1837) (Santiago de Compostela: Imp. de José Fermín Campaña y Aguayo). Reproducido en Prosa galega: 59-60. 
Fandiño, A. B. (2000): A Casamenteira. Introducción de Xosé R. Barreiro, Laura Tato e Carmen Blanco (Ourense: Linteo).

Fernández y Neira, J. (1810): Proezas de Galicia, explicadas baxo la conversación rústica de los dos compadres Chinto y Mingote (Coruña: Imprenta da Vila).

Fernández Rifón, A. (1999): Cabanas, Erines, Laraxe, San Martín do Porto, Regüela, Sta. Cruz do Salto, Soaserra: según las respuestas generales del catrastro de Ensenada, año 1752 y emblemas del municipio (A Coruña: Deputación da Coruña).

Fiestas Minervales, y aclamación perpetua de las Musas, a la inmortal memoria de el Ilustrissimo, y Excelentíssimo señor D. Alonso de Fonseca el Grande por su Escuela y Universidad (1993) [ed. facsímile da ed. de 1697] (Santiago de Compostela: Universidade de Santiago de Compostela).

La Coruña 1752: según las Respuestas Generales del Catastro de Ensenada (1990). Introducción: Baudilio Barreiro (Madrid: Centro de Gestión Catastral y Cooperación Tributaria / Tabapress).

La Tertulia de Picaños (1836) (Santiago: Imprenta de D. J. F. Campaña y Aguayo) Reproducido en Prosa galega: 34-39.

Lema Suárez, X. M (2006): Onomástica histórica dunha parroquia galega: Berdoias (1607-2000). I. Os nomes masculinos (Santiago de Compostela: Asociación Galega de Onomástica).

Pardo de Andrade, M. (1813): Os rogos d'un gallego establecido en Londres, dedicados os seus paysanos para abrirlles os ollos sobre certas iñorancias, e o demais que vera o curioso lector (Coruña, á instancias de varios patriotas amantes del Gobierno y de la Constitución. Caxa tipográfica del Diario).

Pardo de Neyra, X. (2002): O labor lírico do ilustrado cura de Fruíme: textos galegos de Zernadas y Castro [1702-1777] (Santiago de Compostela: Laiovento).

Parola de Cacheiras (1836). Reproducida en Prosa galega: 61-63.

PIsla = Cartas familiares y escogidas del Padre José Francisco de Isla escritas a su hermana María Francisca de Isla y Losada y a su cuñado Nicolás de Ayala desde 1755 a 1781 (1884) (Barcelona: Daniel Cortezo y Ca).

Prosa galega. Desde os primeiros oitocentitas ao grupo Nós (1976) (Cátedra de Lingüística e Literatura Galega da Universidade de Santiago de Compostela).

Saco Arce, J. A. (1967) [1868]: Gramática gallega (Ourense: Graf. Tanco).

Sánchez Rei, X. M. (2006): A lingua galega no cancioneiro de Pérez Ballesteros (Santiago de Compostela: Laiovento).

Santiago de Compostela, 1752: Según las Respuestas Generales del Catastro de Ensenada (1990). Introducción: Antonio Eiras Roel (Madrid: Centro de Gestión Catastral y Cooperación Tributaria / Tabapress).

Sarmiento, M. [1746]: Coloquio en mil duascentas coplas galegas. Facsímile do orixinal autógrafo (Santiago de Compostela: Consello da Cultura Galega. Edición 
divulgativa, feita e anotada por Henrique Monteagudo: s.l.: La Voz de Galicia / Galaxia, 2002).

Tuy 1753: según las respuestas generales del catastro de Ensenada (1990). Introducción: Ofelia Rey Castelao Madrid: Centro de Gestión Catastral y Cooperación Tributaria / Tabapress).

\section{Fontes para os hipocorísticos do séc. XX}

Cancioneiro popular galego (1984-1995). Recollido e ordenado por Dorothé Schubarth e Antón Santamarina. Vols. 1, 2, 4, 5, 6 (A Coruña: Fundación Pedro Barrié de la Maza).

DNG = Ferro Ruibal, X. (dir.) / Boullón Agrelo, A. I. / Lema, J. M. / Tato Plaza, F. R. / García, J. M. (1992): Diccionario dos nomes galegos (Vigo: Ir Indo).

Fernández Rei, F. / Hermida Gulías, C. (eds.) (2003) [1996]: A nosa fala: bloques e áreas lingüísticas do galego (Santiago de Compostela: Consello da Cultura Galega).

Hafner, U. (2004): Namengebung und Namenverhalten im Spanien der 70er Jahre (Tübingen: Max Niemeyer Verlag. Patronymica Romanica 21).

Iglesias González, X. (2005) "Hipocorísticos", Cedofeita: Asociación Socio-Cultural Cedofeita, 9: 15-16.

Santos Gayoso, E. (2002): Diccionario de seudónimos y apodos gallegos (Santiago: Nino).

TILG = Tesouro Informatizado da Lingua Galega do Instituto da Lingua Galega, dirixido por Antón Santamarina. Páxina web: http://www.ti.usc.es/TILG/index/.asp

Torres Regueiro, X. / Cuns Lousa, X. (1989): Alcumes recollidos en Betanzos (Betanzos: Concello). 


\section{Anexo: relación de hipocorísticos}

Para simplificar, e tendo en conta que non en tódolos casos se tiña constancia de cal era a forma oficial á que correspondía o hipocorístico, tendín a regularizar as formas primitivas normalmente coa forma galega, aínda sendo consciente do atrasado que en Galicia está o proceso de re-galeguización da antroponimia. Tódalas formas que están aquí, procedentes de fontes diversas, corresponden a usos reais, de aí que poidan aparecer formas femininas e non as masculinas correspondentes, ou á inversa. Están incluídas as proporcionadas polas fontes do séc. XVII en diante.

\begin{tabular}{|c|c|c|c|}
\hline Nome & $\begin{array}{l}\text { Hipocorísticos } \\
\text { ss. XVII-XIX }\end{array}$ & $\begin{array}{l}\text { Hipocorísticos } \\
\text { s. XX }\end{array}$ & $\begin{array}{c}\text { Novas } \\
\text { tendencias }\end{array}$ \\
\hline Abelardo & & Lalo & \\
\hline Adolfo & & Dolfo & \\
\hline Adoración & & Dora & \\
\hline Adrao & & & Adra \\
\hline Adrián, -na & & & Adri \\
\hline Afonso/Alfonso & & Fonso & $\begin{array}{c}\text { Al } \\
\text { Poncho }\end{array}$ \\
\hline Agostiño/Agustín & Agosto & Justo & Agus \\
\hline \multicolumn{4}{|l|}{ Tin } \\
\hline Agustina & & Tina & \\
\hline Alexandra, -dre & & $\begin{array}{c}\text { Xandra, -dre } \\
\text { Xana-, -no / Jano } \\
\text { Janolo }\end{array}$ & Jandri \\
\hline Alfredo & & Firuco & \\
\hline Alicia & & & Ali \\
\hline Álvaro & & Varo & Varo \\
\hline \multicolumn{4}{|l|}{ Variño } \\
\hline Amalia & & Malucha & \\
\hline Amelia & & $\begin{array}{l}\text { Meluca } \\
\text { Memé }\end{array}$ & \\
\hline Ana & & & Anuska \\
\hline Ana + Isabel & & Anabel & \\
\hline Andrea & & & Andre \\
\hline Andrés & Andruco & $\begin{array}{l}\text { Necho } \\
\text { Nes } \\
\text { Cholo }\end{array}$ & $\begin{array}{c}\text { Nes } \\
\text { Nesuco }\end{array}$ \\
\hline Ángel & & Lito & \\
\hline
\end{tabular}




\begin{tabular}{|c|c|c|c|}
\hline Nome & $\begin{array}{l}\text { Hipocorísticos } \\
\text { ss. XVII-XIX }\end{array}$ & $\begin{array}{l}\text { Hipocorísticos } \\
\text { s. XX }\end{array}$ & $\begin{array}{l}\text { Novas } \\
\text { tendencias }\end{array}$ \\
\hline $\begin{array}{c}\text { Ángela } \\
\text { Anxela, -lo }\end{array}$ & & $\begin{array}{c}\text { Xela, -lo } \\
\text { Xeluca, -co / Geluco } \\
\text { Xelucha, -cho / } \\
\text { Gelucho } \\
\text { Xeli }\end{array}$ & Gelu \\
\hline Angustias & & Pilucha & \\
\hline Anselma & & Selma & \\
\hline Antón/Antonio & Antón & $\begin{array}{c}\text { Antón } \\
\text { Andolas } \\
\text { Antucho } \\
\text { Tucho } \\
\text { Tito } \\
\text { To } \\
\text { Tocho } \\
\text { Tonecho } \\
\text { Toneco } \\
\text { Tono } \\
\text { Toño } \\
\text { Toñico } \\
\text { Totó }\end{array}$ & Anto \\
\hline Antonia & Antoniña & $\begin{array}{l}\text { Tona } \\
\text { Tucha }\end{array}$ & \\
\hline Armando & & & Mando \\
\hline Asunción & & $\begin{array}{l}\text { Xonxa } \\
\text { Chon } \\
\text { Chona } \\
\text { Choncha }\end{array}$ & \\
\hline Avelino & & Lino & \\
\hline Balbina & & Nocha & \\
\hline Baldomero & & Mero & \\
\hline Beatriz & & & $\begin{array}{l}\text { Bucha } \\
\text { Bea } \\
\text { Betty }\end{array}$ \\
\hline Begoña & & & Bego \\
\hline Belén & & & Beliña \\
\hline Benedicta & & & Dita \\
\hline Benigna, -no & & $\begin{array}{l}\text { Benucha,-cho } \\
\text { Nucha,-cho }\end{array}$ & \\
\hline Benito & Beni & Tocho & \\
\hline
\end{tabular}




\begin{tabular}{|c|c|c|c|}
\hline Nome & $\begin{array}{l}\text { Hipocorísticos } \\
\text { ss. XVII-XIX }\end{array}$ & $\begin{array}{l}\text { Hipocorísticos } \\
\text { s. XX }\end{array}$ & $\begin{array}{c}\text { Novas } \\
\text { tendencias }\end{array}$ \\
\hline Bernaldo & & & $\begin{array}{l}\text { Bérnal } \\
\text { Berni }\end{array}$ \\
\hline Bernarda/-do & & $\begin{array}{l}\text { Narda/-do } \\
\text { Nucha/-cho } \\
\text { Lalo }\end{array}$ & \\
\hline $\begin{array}{l}\text { Bertolomeu } \\
\text { /Bartolomeu }\end{array}$ & $\begin{array}{c}\text { Bértolo } \\
\text { Bartolo } \\
\text { Bartoldo }\end{array}$ & $\begin{array}{l}\text { Bértolo } \\
\text { Bartolo }\end{array}$ & \\
\hline Caetana & Caitaniña & & \\
\hline Caetano & & Tano & \\
\hline Candela & & & Luqui \\
\hline Cándida/-do & & $\begin{array}{c}\text { Canducha/-cho } \\
\text { Ducha/-cho } \\
\text { Canucho }\end{array}$ & \\
\hline Carlos & & $\begin{array}{c}\text { Carlucho } \\
\text { Carolo }\end{array}$ & \\
\hline Carme & Carmela & $\begin{array}{l}\text { Carmela } \\
\text { Mela } \\
\text { Lucha } \\
\text { Carmucha } \\
\text { Mucha } \\
\text { Carmuca } \\
\text { Carmiña } \\
\text { Menchu } \\
\text { Chicha }\end{array}$ & $\begin{array}{c}\text { Camy } \\
\text { Carmuna }\end{array}$ \\
\hline Casilda & & Silda & \\
\hline Catarina & Catuxa & Catuxa & \\
\hline Celestina & & Tina & \\
\hline Celestino & & Cilistro & \\
\hline Celso & & Siño & \\
\hline Claudia & & & Clau \\
\hline Concepción & & $\begin{array}{l}\text { Nenuca } \\
\text { Concha } \\
\text { Chicha }\end{array}$ & \\
\hline Constantino & & Tino & \\
\hline Cristina & & & $\begin{array}{l}\text { Crisi } \\
\text { Cris }\end{array}$ \\
\hline Damián & & & Dami \\
\hline Daniel & & & Dani \\
\hline
\end{tabular}




\begin{tabular}{|c|c|c|c|}
\hline Nome & $\begin{array}{l}\text { Hipocorísticos } \\
\text { ss. XVII-XIX }\end{array}$ & $\begin{array}{l}\text { Hipocorísticos } \\
\text { s. XX }\end{array}$ & $\begin{array}{c}\text { Novas } \\
\text { tendencias }\end{array}$ \\
\hline Darío & & Iño & \\
\hline Déborah & & & $\begin{array}{l}\text { Debo } \\
\text { Deb } \\
\text { De }\end{array}$ \\
\hline Diego & & & Queco \\
\hline Dolores & & $\begin{array}{l}\text { Lola } \\
\text { Loli } \\
\text { Lolita } \\
\text { Loló }\end{array}$ & Doly \\
\hline Dominga & $\begin{array}{l}\text { Dominguiña } \\
\text { Minga } \\
\text { Minguiña } \\
\text { Mingota }\end{array}$ & & \\
\hline Domingo(s) & $\begin{array}{l}\text { Mingos } \\
\text { Mingo } \\
\text { Minguiño } \\
\text { Mingote } \\
\text { Mingacho } \\
\text { Mingucho }\end{array}$ & Mingo(s) & \\
\hline Dorotea & & Dora & \\
\hline Edelmira & & Miruca & \\
\hline Edelmiro & & Miro & \\
\hline Eduardo & & $\begin{array}{l}\text { Educho } \\
\text { Chacho } \\
\text { Dito } \\
\text { Ito }\end{array}$ & Edu \\
\hline Eladina & & Dina & \\
\hline Eleuterio & & Telo & \\
\hline Eligio & & Ligucho & \\
\hline Eliseu & & Cholo & \\
\hline Elvira & & $\begin{array}{c}\text { Viruca } \\
\text { Virucha } \\
\text { Viri } \\
\text { Virita }\end{array}$ & \\
\hline Emilia & & $\begin{array}{l}\text { Milucha } \\
\text { Lucha } \\
\text { Miluca } \\
\text { Mila }\end{array}$ & \\
\hline Emilio & & $\begin{array}{l}\text { Miluco } \\
\text { Milucho } \\
\text { Lucho }\end{array}$ & \\
\hline
\end{tabular}




\begin{tabular}{|c|c|c|c|}
\hline Nome & $\begin{array}{l}\text { Hipocorísticos } \\
\text { ss. XVII-XIX }\end{array}$ & $\begin{array}{l}\text { Hipocorísticos } \\
\text { s. XX }\end{array}$ & $\begin{array}{c}\text { Novas } \\
\text { tendencias }\end{array}$ \\
\hline Encarnación & & $\begin{array}{l}\text { Chincha } \\
\text { Encarna }\end{array}$ & \\
\hline Ermesinda & & Sinda & \\
\hline Ernesto & & & Ernes \\
\hline Eugenia, -nio & & $\begin{array}{l}\text { Genucha, -cho } \\
\text { Nucho }\end{array}$ & \\
\hline Eulogio & & $\begin{array}{l}\text { Locho } \\
\text { Gelucho }\end{array}$ & \\
\hline Evaristo & & Suso & \\
\hline Ezequiel & Zaquiel & & \\
\hline Fabiola & & & Fabi \\
\hline Fátima & & & Faty \\
\hline Felipe, Filipe & & $\begin{array}{l}\text { Chelipe } \\
\text { Filucho }\end{array}$ & \\
\hline Fernando & Fernanduco & $\begin{array}{l}\text { Nando } \\
\text { Nano }\end{array}$ & \\
\hline Filomena & & Filucha & \\
\hline Florentina & & Tinucha & \\
\hline Florencia & & Pencha & \\
\hline Florentino & & $\begin{array}{c}\text { Tino } \\
\text { Floro } \\
\text { Tinucho }\end{array}$ & \\
\hline Francisca & Farruca & $\begin{array}{c}\text { Filucha } \\
\text { Farruca } \\
\text { Pacucha } \\
\text { Sisca } \\
\text { Quica }\end{array}$ & \\
\hline Francisco & Farruco & $\begin{array}{c}\text { Fuco } \\
\text { Farruco } \\
\text { Farruquiño } \\
\text { Chisco } \\
\text { Chuco } \\
\text { Franco } \\
\text { Paco } \\
\text { Pacucho } \\
\text { Pachuco } \\
\text { Pucho } \\
\text { Pachicho } \\
\text { Chicho } \\
\text { Pancho } \\
\text { Panchulo } \\
\text { Quico }\end{array}$ & $\begin{array}{c}\text { Fran } \\
\text { Chesco } \\
\text { Quico }\end{array}$ \\
\hline
\end{tabular}




\begin{tabular}{|c|c|c|c|}
\hline Nome & $\begin{array}{l}\text { Hipocorísticos } \\
\text { ss. XVII-XIX }\end{array}$ & $\begin{array}{l}\text { Hipocorísticos } \\
\text { s. XX }\end{array}$ & $\begin{array}{c}\text { Novas } \\
\text { tendencias }\end{array}$ \\
\hline Gonzalo & Zalo & $\begin{array}{l}\text { Cholo } \\
\text { Chalo }\end{array}$ & \\
\hline Gregorio & $\begin{array}{l}\text { Gorecho } \\
\text { Goriño }\end{array}$ & $\begin{array}{c}\text { Goro } \\
\text { Gorecho } \\
\text { Goros }\end{array}$ & Goro \\
\hline Gumersinda & & Chinda & \\
\hline Gumersindo & & Sindo & \\
\hline Helena & & $\begin{array}{l}\text { Lenuca } \\
\text { Chiqui } \\
\text { Queca }\end{array}$ & $\begin{array}{l}\text { Lena } \\
\text { Leni }\end{array}$ \\
\hline Henrique & & $\begin{array}{c}\text { Ricucho } \\
\text { Rico } \\
\text { Quique } \\
\text { Queco } \\
\text { Cholo }\end{array}$ & Quique \\
\hline Hilario & & Lalo & \\
\hline Honorinda & & Nonda & \\
\hline Ignacio & & Nacho & \\
\hline Inés & & & Ine \\
\hline Inmaculada & & $\begin{array}{l}\text { Inma } \\
\text { Macu }\end{array}$ & \\
\hline Inocencia/cio & & $\begin{array}{c}\text { Chencha/cho } \\
\text { Xenxa/xo }\end{array}$ & \\
\hline Iria & & & Iri \\
\hline Isabel & $\begin{array}{l}\text { Sabel } \\
\text { Sabela }\end{array}$ & $\begin{array}{l}\text { Sabela } \\
\text { Xabela } \\
\text { Beluca } \\
\text { Chicha }\end{array}$ & Isa \\
\hline Isidoro & & Doro & \\
\hline Isidro & & Sidro & \\
\hline Ismael & & Maelo & \\
\hline Iván & & & Ivi \\
\hline Javier & & & Javucho \\
\hline Jonathan & & & Jon \\
\hline Jorge & & & $\begin{array}{l}\text { Coque } \\
\text { Jorgito }\end{array}$ \\
\hline Lara & & & Larecha \\
\hline Laura & & & Lauriña \\
\hline
\end{tabular}




\begin{tabular}{|c|c|c|c|}
\hline Nome & $\begin{array}{l}\text { Hipocorísticos } \\
\text { ss. XVII-XIX }\end{array}$ & $\begin{array}{l}\text { Hipocorísticos } \\
\text { s. XX }\end{array}$ & $\begin{array}{c}\text { Novas } \\
\text { tendencias }\end{array}$ \\
\hline Laureano & & Nito & \\
\hline Leonardo & & $\begin{array}{l}\text { Xoxardo } \\
\text { Nardo }\end{array}$ & \\
\hline Leopoldina & & Polda & \\
\hline Leticia & & & Leti \\
\hline Lisardo & & Lito & \\
\hline Lorena & & & $\begin{array}{l}\text { Loren } \\
\text { Lore } \\
\text { Loro } \\
\text { Lo }\end{array}$ \\
\hline Lourenzo & & Tito & \\
\hline Lucía & & & $\begin{array}{l}\text { Luci } \\
\text { Luchi } \\
\text { Lu }\end{array}$ \\
\hline Luciano & & $\begin{array}{c}\text { Tano } \\
\text { Chano } \\
\text { Luchano }\end{array}$ & \\
\hline Luís & & Iño & Luilli \\
\hline Luísa & & $\begin{array}{l}\text { Lis } \\
\text { Sisa }\end{array}$ & \\
\hline Luz & & Lucita & \\
\hline Lydia & & & Lydi \\
\hline Madalena & & Mada & \\
\hline Manuel & & $\begin{array}{l}\text { Manolo } \\
\text { Noli } \\
\text { Lolo } \\
\text { Lito } \\
\text { Locho } \\
\text { Nel } \\
\text { Nelo } \\
\text { Lelo } \\
\text { Manecho } \\
\text { Maecho } \\
\text { Cholo }\end{array}$ & Manu \\
\hline Manuela & & $\begin{array}{l}\text { Manola } \\
\text { Nola } \\
\text { Noli } \\
\text { Lita } \\
\text { Lela } \\
\text { Nela }\end{array}$ & \\
\hline Marcelina, -no & & Nucha/-cho & \\
\hline
\end{tabular}




\begin{tabular}{|c|c|c|c|}
\hline Nome & $\begin{array}{l}\text { Hipocorísticos } \\
\text { ss. XVII-XIX }\end{array}$ & $\begin{array}{l}\text { Hipocorísticos } \\
\text { s. XX }\end{array}$ & $\begin{array}{c}\text { Novas } \\
\text { tendencias }\end{array}$ \\
\hline Marcos & & & Marquiños \\
\hline Margarida/Margarita & & $\begin{array}{l}\text { Marga } \\
\text { Magú }\end{array}$ & \\
\hline María & $\begin{array}{c}\text { Marica } \\
\text { Mariquiña } \\
\text { Maruxa } \\
\text { Maruxiña }\end{array}$ & $\begin{array}{l}\text { Maruxa } \\
\text { Maruxela } \\
\text { Marucha } \\
\text { Marica } \\
\text { Mariquiña } \\
\text { Maruca } \\
\text { Marucha } \\
\text { Maúca } \\
\text { Uca } \\
\text { Miúca } \\
\text { Machuca }\end{array}$ & Mery \\
\hline María + Carme & & $\begin{array}{c}\text { Maca } \\
\text { Maica } \\
\text { Marita } \\
\text { Menani }\end{array}$ & \\
\hline María + Dolores & & $\begin{array}{c}\text { Mariló } \\
\text { Maló } \\
\text { Maloles } \\
\text { Madó }\end{array}$ & \\
\hline María + Elisa & & Mariela & \\
\hline María + Ester & & Marité & \\
\hline María + Helena & & Malena & \\
\hline María + Isabel & & $\begin{array}{c}\text { Maribel } \\
\text { Mabel }\end{array}$ & \\
\hline María + Lidia & & Marilí & \\
\hline María + Luísa & & $\begin{array}{l}\text { Marisa } \\
\text { Marilís }\end{array}$ & \\
\hline María + Luz & & Malú & \\
\hline María + Mar & & Marimar & \\
\hline María + Rosa & & Marosa & \\
\hline María + Tereixa & & $\begin{array}{l}\text { Maite } \\
\text { Marité }\end{array}$ & \\
\hline María + Virtudes & & Mariví & \\
\hline María + Xesús & & $\begin{array}{l}\text { Chus } \\
\text { Chusa } \\
\text { Chuchú } \\
\text { Chuchi } \\
\text { Maruchi }\end{array}$ & \\
\hline
\end{tabular}




\begin{tabular}{|c|c|c|c|}
\hline Nome & $\begin{array}{l}\text { Hipocorísticos } \\
\text { ss. XVII-XIX }\end{array}$ & $\begin{array}{l}\text { Hipocorísticos } \\
\text { s. XX }\end{array}$ & $\begin{array}{c}\text { Novas } \\
\text { tendencias }\end{array}$ \\
\hline María + Xosé/Xosefa & & $\begin{array}{l}\text { Marisé } \\
\text { Maripepa } \\
\text { Sesé }\end{array}$ & \\
\hline Marina (cast.) & & Marinocha & \\
\hline Marta & & Martula & \\
\hline Martín, Martiño & & Tiñolo & Tin \\
\hline Matilde & & $\begin{array}{c}\text { Matucha } \\
\text { Matuca } \\
\text { Matusa } \\
\text { Tilda } \\
\text { Duca }\end{array}$ & \\
\hline Maximino & & & Maxi \\
\hline Mercedes & & $\begin{array}{l}\text { Merche } \\
\text { Chedes } \\
\text { Chiruca }\end{array}$ & Merchi \\
\hline Miguel & & & $\begin{array}{l}\text { Migue } \\
\text { Mich } \\
\text { Míchel } \\
\text { Míkel }\end{array}$ \\
\hline Milagros & & Mila & \\
\hline Mónica & & & Moni \\
\hline Montserrat & & Monse & Mont \\
\hline Natividad & & Chelo & Natiña \\
\hline Nélida & & & Neli \\
\hline Nerea & & & $\begin{array}{l}\text { Nere } \\
\mathrm{Ne}\end{array}$ \\
\hline Noelia & & & $\begin{array}{c}\text { Noe } \\
\text { Neli } \\
\text { Noeliña }\end{array}$ \\
\hline Norberto & & & Nórber \\
\hline Olalla & & & Oli \\
\hline Olegario & & Garucho & \\
\hline Óscar & & Tucho & $\begin{array}{c}\text { Osca } \\
\text { Osquíñar }\end{array}$ \\
\hline Otilia & & Tila & \\
\hline Pablo & & & $\begin{array}{l}\text { Pablito } \\
\text { Pa }\end{array}$ \\
\hline Patricia & & & $\begin{array}{c}\text { Patri } \\
\text { Pati/Patty }\end{array}$ \\
\hline
\end{tabular}




\begin{tabular}{|c|c|c|c|}
\hline Nome & $\begin{array}{l}\text { Hipocorísticos } \\
\text { ss. XVII-XIX }\end{array}$ & $\begin{array}{l}\text { Hipocorísticos } \\
\text { s. XX }\end{array}$ & $\begin{array}{c}\text { Novas } \\
\text { tendencias }\end{array}$ \\
\hline Pedro & $\begin{array}{l}\text { Perucho } \\
\text { Perico } \\
\text { Periquiño } \\
\text { Pedriño }\end{array}$ & $\begin{array}{l}\text { Perucho } \\
\text { Peruxo } \\
\text { Perico }\end{array}$ & \\
\hline Perfecto & & Chicho & \\
\hline Piedad & & Piti & \\
\hline Pilar & Pilara & $\begin{array}{c}\text { Pilocha } \\
\text { Pitusa } \\
\text { Piruca } \\
\text { Pilara } \\
\text { Pili }\end{array}$ & Piluchi \\
\hline Plácido & & Pacho & \\
\hline Presentación & & Presenta & \\
\hline Prudencia & & Pencha & \\
\hline Purificación & & $\begin{array}{l}\text { Porfica } \\
\text { Pura }\end{array}$ & \\
\hline Rafael & & $\begin{array}{l}\text { Felo } \\
\text { Lucho } \\
\text { Chiño }\end{array}$ & \\
\hline Raimundo & & $\begin{array}{l}\text { Mundo } \\
\text { Rai }\end{array}$ & \\
\hline Ramiro & & Miro & Rami \\
\hline Ramón & & Moncho & \\
\hline Raquel & & & $\begin{array}{c}\text { Raqui/Raquy/Racky } \\
\text { Rachy } \\
\text { Ra } \\
\text { Queli/Kely/Quely }\end{array}$ \\
\hline Regina & & $\begin{array}{c}\text { Gina } \\
\text { Ginocha }\end{array}$ & \\
\hline Remedios & & Reme & \\
\hline Ricardo & & $\begin{array}{l}\text { Cardocho } \\
\text { Carducho } \\
\text { Tito }\end{array}$ & $\begin{array}{l}\text { Riki/Ricky } \\
\text { Richard } \\
\text { Richi }\end{array}$ \\
\hline Rita & & Chuca & \\
\hline Rocío & & & $\begin{array}{l}\text { Xío } \\
\text { Ro }\end{array}$ \\
\hline Rodrigo & & & Rodri \\
\hline Rosa & & Coca & \\
\hline Rosalía & & Chelía & \\
\hline Rosario & Chicha & $\begin{array}{l}\text { Rosy } \\
\text { Charo } \\
\text { Chara }\end{array}$ & $\begin{array}{l}\text { Rosi } \\
\text { Ro }\end{array}$ \\
\hline
\end{tabular}




\begin{tabular}{|c|c|c|c|}
\hline Nome & $\begin{array}{l}\text { Hipocorísticos } \\
\text { ss. XVII-XIX }\end{array}$ & $\begin{array}{l}\text { Hipocorísticos } \\
\text { s. XX }\end{array}$ & $\begin{array}{c}\text { Novas } \\
\text { tendencias }\end{array}$ \\
\hline Rubén & & & $\begin{array}{l}\text { Rubi } \\
\text { Rugui } \\
\text { Ruchi }\end{array}$ \\
\hline Sabela & & & Sabe \\
\hline Sabrina & & & Sabri \\
\hline Salvador & & Pachucho & \\
\hline Sandra & & & Sandy \\
\hline Santiago & & $\begin{array}{l}\text { Chago } \\
\text { Santi }\end{array}$ & \\
\hline Sebastián & Bastián & & \\
\hline Serafín & & Fincholo & \\
\hline Serafina & & Fina & \\
\hline Silvia & & & $\begin{array}{l}\text { Silvi } \\
\text { Sil }\end{array}$ \\
\hline Sofía & & & Sofi \\
\hline Soledad & & Solita & \\
\hline Sonia & & & $\begin{array}{l}\text { Soni } \\
\text { Soñi } \\
\text { Son }\end{array}$ \\
\hline Soraya & & & $\begin{array}{l}\text { Sora } \\
\text { Sori }\end{array}$ \\
\hline Susana & & & $\begin{array}{c}\text { Susan } \\
\text { Susi/Susy }\end{array}$ \\
\hline Tamara & & & Tami \\
\hline Tereixa/Teresa & & $\begin{array}{l}\text { Teruca } \\
\text { Suca } \\
\text { Terucha } \\
\text { Terela } \\
\text { Teté }\end{array}$ & \\
\hline Trindade & & Trina & \\
\hline Úrsula & & & Úa \\
\hline Valentín & & $\begin{array}{l}\text { Vitín } \\
\text { Neco }\end{array}$ & \\
\hline Valentina & & Tina & \\
\hline Vanesa, Vanessa & & & $\begin{array}{c}\text { Vane } \\
\text { Vani } \\
\text { Nessa } \\
\text { Vanesiña }\end{array}$ \\
\hline Venancio & & Zalo & \\
\hline Verónica & & & $\begin{array}{l}\text { Vero } \\
\text { Veri }\end{array}$ \\
\hline
\end{tabular}




\begin{tabular}{|c|c|c|c|}
\hline Nome & $\begin{array}{l}\text { Hipocorísticos } \\
\text { ss. XVII-XIX }\end{array}$ & $\begin{array}{l}\text { Hipocorísticos } \\
\text { s. XX }\end{array}$ & $\begin{array}{c}\text { Novas } \\
\text { tendencias }\end{array}$ \\
\hline Vicente & & $\begin{array}{l}\text { Chente } \\
\text { Vituco } \\
\text { Cholas }\end{array}$ & \\
\hline Vítor & & $\begin{array}{c}\text { Vituco } \\
\text { Vitolo } \\
\text { Vitocho }\end{array}$ & \\
\hline Vitoria & & $\begin{array}{l}\text { Totora } \\
\text { Toya } \\
\text { Viqui }\end{array}$ & \\
\hline Xabier/Xavier & & Xavi (Javi) & \\
\hline Xacinto & Chinto & Chinto & \\
\hline Xaime & & & Mucho \\
\hline Xertrudes & Xêtrudiñas & & \\
\hline Xesús & & $\begin{array}{l}\text { Suso } \\
\text { Susete } \\
\text { Xuxo } \\
\text { Chucho } \\
\text { Chechu } \\
\text { Cuchús }\end{array}$ & $\begin{array}{l}\text { Chechu } \\
\text { Chucho }\end{array}$ \\
\hline Xesús + María & & Chumi & \\
\hline Xesusa & & Susa & \\
\hline Xoán / Juan & $\begin{array}{c}\text { Xan } \\
\text { Xaniño }\end{array}$ & $\begin{array}{c}\text { Xan } \\
\text { Nucho } \\
\text { Xanocas } \\
\text { Xanzolo } \\
\text { Xanzolas } \\
\text { Juanito } \\
\text { Juansiño }\end{array}$ & \\
\hline Juan + Carlos & & & Juanca \\
\hline Xoán + Xosé & & Xanxo & \\
\hline Xoana & $\begin{array}{l}\text { Joaniña } \\
\text { Janiña }\end{array}$ & $\begin{array}{c}\text { Nucha } \\
\text { Xana } \\
\text { Chucha }\end{array}$ & \\
\hline $\begin{array}{l}\text { Xoaquín } \\
\text { Quinocho }\end{array}$ & $\begin{array}{l}\text { Xaquín } \\
\text { Xoquín }\end{array}$ & $\begin{array}{l}\text { Xaquín } \\
\text { Xoquín } \\
\text { Xocas } \\
\text { Xoco } \\
\text { Quin } \\
\text { Quino }\end{array}$ & \\
\hline Xoaquina & & $\begin{array}{l}\text { Nocha } \\
\text { Quinola } \\
\text { Xaquina }\end{array}$ & \\
\hline
\end{tabular}




\begin{tabular}{|c|c|c|c|}
\hline Nome & $\begin{array}{l}\text { Hipocorísticos } \\
\text { ss. XVII-XIX }\end{array}$ & $\begin{array}{l}\text { Hipocorísticos } \\
\text { s. XX }\end{array}$ & $\begin{array}{c}\text { Novas } \\
\text { tendencias }\end{array}$ \\
\hline Xosé / José & $\begin{array}{l}\text { Chisepe } \\
\text { Xepe } \\
\text { Xepiño } \\
\text { Pepe }\end{array}$ & $\begin{array}{c}\text { Che } \\
\text { Cheíño } \\
\text { Cheché } \\
\text { Xe } \\
\text { Pepe } \\
\text { Pepucho } \\
\text { Pepote } \\
\text { Pepito } \\
\text { Piño } \\
\text { Pucho } \\
\text { Pepiño / Pepín } \\
\text { Seso } \\
\text { Joseíño } \\
\text { Sito } \\
\text { Josito } \\
\text { Josiño } \\
\text { Josecho }\end{array}$ & $\begin{array}{c}\text { Xose } \\
\text { Xos } \\
\text { Xo }\end{array}$ \\
\hline Xosé + Luís & & $\begin{array}{l}\text { Xelís } \\
\text { Chelís } \\
\text { Cholo } \\
\text { Lilís }\end{array}$ & \\
\hline Xosé + Manuel & & $\begin{array}{l}\text { Cheto } \\
\text { Cochecho }\end{array}$ & \\
\hline Xosé + María & & $\begin{array}{l}\text { Chema } \\
\text { Chemari }\end{array}$ & \\
\hline Xosefa / Josefa & Pepa & $\begin{array}{c}\text { Pepa } \\
\text { Pepucha } \\
\text { Pepita } \\
\text { Pepitiña } \\
\text { Chefa } \\
\text { Checha } \\
\text { Fefa } \\
\text { Sesa } \\
\text { Sefa } \\
\text { Xefa } \\
\text { Fita } \\
\text { Fitucha } \\
\text { Pirucha } \\
\text { Pitusa }\end{array}$ & \\
\hline Xosefina / Josefina & & $\begin{array}{c}\text { Fina } \\
\text { Finuca }\end{array}$ & \\
\hline Xulia / Julia & & & $\mathrm{Ju}$ \\
\hline Yolanda & & & $\begin{array}{l}\text { Yola } \\
\text { Yoli } \\
\text { Yoliña } \\
\text { Landa }\end{array}$ \\
\hline
\end{tabular}

